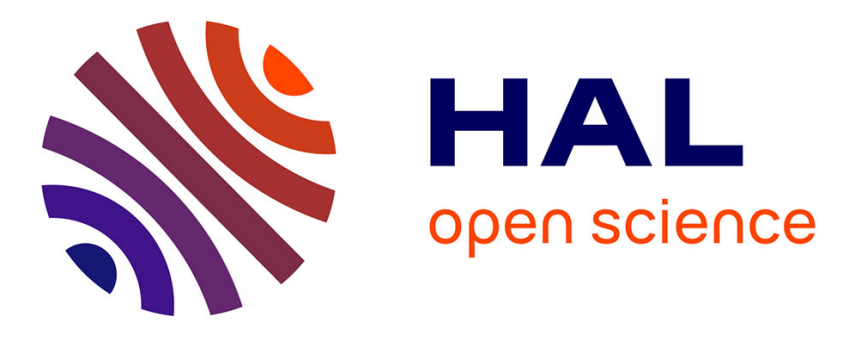

\title{
NRT2.1 phosphorylation prevents root high affinity nitrate uptake activity in Arabidopsis thaliana
}

Aurore Jacquot, Valentin Chaput, Adeline Mauriès, Zhi Li, Pascal Tillard, Cécile Fizames, Pauline Bonillo, Fanny Bellegarde, Edith Laugier, Veronique Santoni, et al.

\section{To cite this version:}

Aurore Jacquot, Valentin Chaput, Adeline Mauriès, Zhi Li, Pascal Tillard, et al.. NRT2.1 phosphorylation prevents root high affinity nitrate uptake activity in Arabidopsis thaliana. 2019. hal-02104665

\section{HAL Id: hal-02104665 \\ https://hal.science/hal-02104665}

Preprint submitted on 19 Apr 2019

HAL is a multi-disciplinary open access archive for the deposit and dissemination of scientific research documents, whether they are published or not. The documents may come from teaching and research institutions in France or abroad, or from public or private research centers.
L'archive ouverte pluridisciplinaire HAL, est destinée au dépôt et à la diffusion de documents scientifiques de niveau recherche, publiés ou non, émanant des établissements d'enseignement et de recherche français ou étrangers, des laboratoires publics ou privés. 


\section{Title Page}

NRT2.1 phosphorylation prevents root high affinity nitrate uptake activity in Arabidopsis thaliana

Aurore Jacquot ${ }^{\mathrm{a}}$, Valentin Chaput ${ }^{\mathrm{a}}$, Adeline Mauries ${ }^{\mathrm{a}}, \mathrm{Zhi} \mathrm{Li}^{\mathrm{b}}$, Pascal Tillard ${ }^{\mathrm{a}}$, Cécile Fizames ${ }^{\mathrm{a}}$, Pauline Bonillo ${ }^{\mathrm{a}}$, Fanny Bellegarde ${ }^{\mathrm{a}}$, Edith Laugier ${ }^{\mathrm{a}}$,Véronique Santoni ${ }^{\mathrm{a}}$, Sonia Hem ${ }^{\mathrm{a}}$, Antoine Martin $^{\mathrm{a}}$, Alain Gojon ${ }^{\mathrm{a}}$, Waltraud Schulze ${ }^{\mathrm{b}}$, Laurence Lejay ${ }^{\mathrm{a}, 1}$

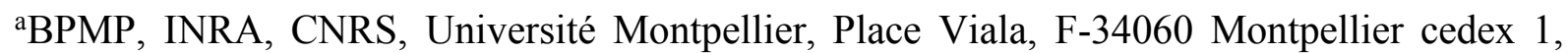
France

${ }^{b}$ Institute of Physiology and Biotechnology of plants, Plant Systems Biology, University of Hohenheim, Garbenstrasse 30, 70593, Stuttgart, Germany

\section{Corresponding author:}

${ }^{1}$ Address correspondence to laurence.lejay@inra.fr

Running title: Post-translational regulation of NRT2.1

Keywords: root nitrate uptake, nitrate transporter, post-translational regulation, phosphorylation, Arabidopsis thaliana, NRT2.1 
bioRxiv preprint first posted online Mar. 20, 2019; doi: http://dx.doi.org/10.1101/583542. The copyright holder for this preprint (which was not peer-reviewed) is the author/funder, who has granted bioRxiv a license to display the preprint in perpetuity.

All rights reserved. No reuse allowed without permission.

\begin{abstract}
In Arabidopsis thaliana, NRT2.1 codes for a main component of the root nitrate high-affinity transport system. Previous studies revealed that post-translational regulation of NRT2.1 plays an important role in the control of root nitrate uptake and that one mechanism could correspond to NRT2.1 C-terminus processing. To further investigate this hypothesis, we produced transgenic plants with truncated forms of NRT2.1. It revealed an essential sequence for NRT2.1 activity, located between the residues 494-513. Using a phospho-proteomic approach, we found that this sequence contains one phosphorylation site, at serine 501, which can inactivate NRT2.1 function when mimicking the constitutive phosphorylation of this residue in transgenic plants. This phenotype could neither be explained by changes in abundance of NRT2.1 and NAR2.1, a partner protein of NRT2.1, nor by a lack of interaction between these two proteins. Finally, the relative level of serine 501 phosphorylation was found to be modulated by nitrate in wildtype plants. Altogether, these observations allowed us to propose a model for a new and essential mechanism for the regulation of NRT2.1 activity.
\end{abstract}




\section{Introduction}

The uptake of nitrate $\left(\mathrm{NO}_{3}^{-}\right)$by plants from the soil solution is ensured by specific transport systems located at the plasma membrane of root cells (Krapp et al., 2014; O'Brien et al., 2016; Wang et al., 2018). In the model plant Arabidopsis thaliana, genes encoding root membrane $\mathrm{NO}_{3}{ }^{-}$transporters have been mainly found in two separate families $N R T 1(N P F)$ and $N R T 2$. In general, NRT1 proteins are low-affinity transport systems (LATS), whereas NRT2 proteins correspond to high-affinity transport system (HATS) (Miller et al., 2007; Tsay et al., 2007). To date, only NRT1.1, NRT1.2, NRT2.1, NRT2.2, NRT2.4 and NRT2.5 were shown to play a key role in the root uptake of $\mathrm{NO}_{3}{ }^{-}$(Tsay et al., 1993; Huang et al., 1999; Filleur et al., 2001; Kiba et al., 2012; Lezhneva et al., 2014). However, it is clear that the HATS activity is predominantly dependent on the NRT2.1 protein. Null-mutants for NRT2.1 have lost up to 75\% of the HATS activity (Cerezo et al., 2001; Filleur et al., 2001; Li et al., 2007), and consequently cannot grow normally with $\mathrm{NO}_{3}{ }^{-}$as sole $\mathrm{N}$ source when provided at a low concentration (e.g., $<1 \mathrm{mM}$ ), (Orsel et al., 2004).

The regulation of NRT2.1 has been mostly studied at the mRNA level. In particular, it has been shown that NRT2.1 is induced upon initial $\mathrm{NO}_{3}{ }^{-}$supply (Lejay et al., 1999; Girin et al., 2007) repressed by nitrogen $(\mathrm{N})$ metabolites or high $\mathrm{NO}_{3}{ }^{-}$provision (Lejay et al., 1999; Gansel et al., 2001; Munos et al., 2004; Krouk et al., 2006; Girin et al., 2007), and up-regulated by light and sugars (Lejay et al., 1999; Lejay et al., 2003; Lejay et al., 2008). However, previous studies suggest that in addition to transcriptional regulation, protein-protein interactions and posttranslational regulation of NRT2.1 might play an important role in modulating the activity of this $\mathrm{NO}_{3}{ }^{-}$transporter. First, despite its firmly established role in root $\mathrm{NO}_{3}{ }^{-}$uptake, NRT2.1 protein alone does not seem to display a $\mathrm{NO}_{3}{ }^{-}$transport activity. To be functional, the Arabidopsis NRT2.1 transport system requires, like in Chlamydomonas reinhardtii and barley, an additional component called NAR2.1 (also called NRT3.1), a protein with a single transmembrane domain (Quesada et al., 1994; Tong et al., 2005; Okamoto et al., 2006; Orsel et al., 2006). Indeed, both gene products need to be co-expressed to yield $\mathrm{NO}_{3}{ }^{-}$uptake in Xenopus oocytes (Orsel et al., 2006), and nar2.1 null mutants lack the NRT2.1 protein at the plasma membrane (Wirth et al., 2007), and are strongly deficient in $\mathrm{NO}_{3}{ }^{-}$HATS (Okamoto et al., 2006; Orsel et al., 2006). The precise function of NAR2.1 remains unclear, but it has been proposed that the active form of the transporter is in fact a NRT2.1/NAR2.1 hetero-oligomer (Yong et al., 2010). Second, the abundance of NRT2.1 protein in the plasma membrane shows much slower changes than those of the $\mathrm{NO}_{3}{ }^{-}$HATS activity in response to light, sugars and high $\mathrm{N}$ 
supply, suggesting activation/inactivation of the NRT2.1/NAR2.1 transport system at the plasma membrane. whereas much faster changes in NRT2.1 mRNA or $\mathrm{NO}_{3}{ }^{-} \mathrm{HATS}$ activity have been demonstrated (Wirth et al., 2007; Laugier et al., 2012).

In spite of the above evidence supporting a possible posttranslational regulation of NRT2.1, the underlying mechanisms are unclear, and several hypotheses can be put forward. First, the association/dissociation dynamics of the NRT2.1/NAR2.1 hetero-dimer can correspond to such a mechanism. However, it has never been reported that this dynamics is regulated and that it actually modulates the activity of the NRT2.1/NAR2.1 transport system. Second, NRT2.1 seems to be subjected to partial proteolysis as it was shown using NRT2.1-GFP plants (Wirth et al., 2007). The possible role of this partial proteolysis is still unknown but the fact that the NRT2.1 truncated part of NRT2.1-GFP, that remains in the plasma membrane (PM), was still recognized by the anti-NRT2.1 20 antibody, which targets an epitope located 18 amino acids upstream of the C terminus of NRT2.1, suggested that the cleavage site is located in or after this epitope. This highlights a putative processing of the C-terminal part of NRT2.1 as a mechanism for controlling its activity. Third, three phosphorylation sites have been found for NRT2.1 in two phospho-proteomic approaches in response to N (Engelsberger and Schulze, 2012; Menz et al., 2016). Among them, NRT2.1 seems to be phosphorylated at S28 when plants are starved with $\mathrm{N}$ and rapidly dephosphorylated upon resupply of $\mathrm{NO}_{3}{ }^{-}$(Engelsberger and Schulze, 2012). It suggests that, as for many membrane transport proteins, posttranslational modifications through phosphorylation are involved to control NRT2.1 activity in response to environmental cues. This conclusion fits with those of concomitant studies which demonstrated that phosphorylation of NRT2.1 ortholog in the yeast Pichia angusta (formerly known as $H$. polymorpha) (YNT1) is required for its delivery to the plasma membrane in response to $\mathrm{N}$ limitation (Navarro et al., 2008).

Another aspect, which could involve the occurrence of post-translational modifications, concerns the role of NRT2.1 in the control of root development in a way that is independent from its transport activity (Little et al., 2005; Remans et al., 2006). This gave rise to the hypothesis that NRT2.1, like NRT1.1, may also be a $\mathrm{NO}_{3}{ }^{-}$sensor, or a signal transducer, but the mechanisms involved are still not known (Little et al., 2005). However, since the sensing function of NRT1.1 depends on NRT1.1 phosphorylation at T101 (Ho et al., 2009; Bouguyon et al., 2015), it supports the hypothesis that post-translational modifications of NRT2.1 could also be involved in the sensing function of NRT2.1.

To explore further and characterise the role of NRT2.1 post-translational modifications we combined the identification of NRT2.1 phosphorylation sites with the production of transgenic 
plants truncated in NRT2.1 C-terminus or carrying point mutations to mimic or prevent NRT2.1 phosphorylation. It allowed us to reveal the importance of the phosphorylation site S501 for NRT2.1 root $\mathrm{NO}_{3}{ }^{-}$uptake activity and to propose a model for a new and essential mechanism for NRT2.1 post-translational regulation.

\section{Results}

\section{NRT2.1 C-terminal part is required for root $\mathrm{NO}_{3}{ }^{-}$uptake activity}

Based on our previous study showing evidence for partial proteolysis of NRT2.1 at the Cterminus (Wirth et al., 2007), we investigated a putative role for NRT2.1 C-terminus on the activity of this transporter by generating transgenic plants expressing truncated forms of NRT2.1 in the nrt2.1-2 knock-out mutant under the control of the NRT2.1 promoter. Two different forms of NRT2.1 were produced, truncated either at the beginning (Plants $\Delta \mathrm{C}_{494-530}$ ) or at the end (Plants $\left.\Delta \mathrm{C}_{514-530}\right)$ of the epitope of anti-NRT2.1 20 antibody (Figure 1). For each construct, two independent transgenic lines $\left(\Delta 3 \mathrm{C}_{494-530}, \Delta 5 \mathrm{C}_{494-530}\right)$ and $\left(\Delta 3 \mathrm{C}_{514-530,} \Delta 6 \mathrm{C}_{514-530}\right)$ were selected based on the correct expression and regulation of the transgenes in response to $\mathrm{NO}_{3}{ }^{-}$induction compared to WT plants (Figure 2C). Strikingly, the $\Delta \mathrm{C}_{494-530}$ plants supplied with $1 \mathrm{mM} \mathrm{NO}_{3}{ }^{-}$displayed a dramatic growth deficiency phenotype, similar to the one observed in the nrt2.1-2 mutant (Figure 2A). On the contrary, the growth phenotype of the $\Delta \mathrm{C}_{514-530}$ plants was similar to the WT, suggesting efficient complementation of nrt2.1-2 mutant by the pNRT2.1::NRT2.1 $\triangle C_{514-530}$ transgene. This indicates that the $\mathrm{C}$ terminal part, between residues 494 and 513 and largely corresponding to the sequence of the epitope of anti-NRT2.1 20 antibody, is strictly required for correct NRT2.1 function (Figure 2A). To confirm this result, $\mathrm{NO}_{3}{ }^{-}$HATS activity, determined by root ${ }^{15} \mathrm{NO}_{3}{ }^{-}$influx assays $\left(0.2 \mathrm{mM}\right.$ external ${ }^{15} \mathrm{NO}_{3}{ }^{-}$ concentration), was characterized in all lines in response to $\mathrm{NO}_{3}{ }^{-}$induction, were performed (Figure 2B). In this experiment, plants were starved for $\mathrm{N}$ for 5 days and transferred during $4 \mathrm{~h}$ and $7 \mathrm{~h}$ on $1 \mathrm{mM} \mathrm{NO}_{3}{ }^{-}$. As expected, this treatment strongly stimulated both $\mathrm{NO}_{3}{ }^{-}$influx (between 5 and 6-fold after $4 \mathrm{~h}$ and $7 \mathrm{~h}$ on $1 \mathrm{mM} \mathrm{NO}_{3}{ }^{-}$) and $N R T 2.1$ expression in WT plants but not in nrt2.1-2 mutant, confirming that $\mathrm{NO}_{3}{ }^{-}$HATS regulation in those conditions was mainly due to NRT2.1 activity (Figures 2B and 2C). Interestingly and in agreement with the growth phenotypes, root $\mathrm{NO}_{3}{ }^{-}$influx was induced by $\mathrm{NO}_{3}{ }^{-}$in $\Delta \mathrm{C}_{514-530}$ plants almost like in the WT but not in $\Delta \mathrm{C}_{494-530}$ plants, where it remains at a low level, similar to that in nrt2.1-2, while NRT2.1 expression was normally induced in both $\Delta \mathrm{C}_{514-530}$ and $\Delta \mathrm{C}_{494-530}$ plants (Figures $2 \mathrm{~B}$ and $2 \mathrm{C}$ ). 
Moreover, this lack of $\mathrm{NO}_{3}^{-}$induction was not the only mis-regulation of root $\mathrm{NO}_{3}^{-}$influx observed in $\Delta \mathrm{C}_{494-530}$ plants as responses to high $\mathrm{N}$, light and sugar were also strongly altered. Indeed, in $\Delta \mathrm{C}_{494-530}$ plants both the repression of root $\mathrm{NO}_{3}{ }^{-}$influx by provision of $10 \mathrm{mM}$ $\mathrm{NH}_{4} \mathrm{NO}_{3}$ and its induction by light or $1 \%$ sucrose were, like in nrt2.1-2 mutant, almost abolished compared to WT and $\Delta \mathrm{C}_{514-530}$ plants (Supplemental Figures $1 \mathrm{~A}$ and 1B). It confirmed that the C-terminal part of NRT2.1 corresponding to 494-513 sequence is required for correct NRT2.1 activity and regulation in a large variety of experimental conditions.

To further investigate the reasons of the lowered HATS activity in $\Delta \mathrm{C}_{494-530}$ plants measurements of NAR2.1 expression and NRT2.1 and NAR2.1 protein levels were performed in response to $\mathrm{NO}_{3}{ }^{-}$. Indeed, a possibility would be that in addition to a specific effect on NRT2.1 activity, NRT2.1 truncation in $\Delta \mathrm{C}_{494-530}$ plants affects the activity and regulation of the NRT2.1/NAR2.1 complex through altered NRT2.1 and/or NAR2.1 expression and/or stability in these plants. Therefore, mRNA and PM fractions were isolated from plants starved for $\mathrm{N}$ for 5 days or transferred during $4 \mathrm{~h}$ on $1 \mathrm{mM} \mathrm{NO}^{-}$. The qRT-PCR and Western blot results showed that neither NAR2.1 gene expression nor its protein level were affected in $\Delta \mathrm{C}_{494-530}$ plants compared to $\Delta \mathrm{C}_{514-530}$ and WT plants (Figures 2D, 3A and 3B). For NRT2.1, western blots performed with Anti-NRT2.1 20 antibody confirmed that the C-terminus part containing the epitope is absent in $\Delta \mathrm{C}_{494-530}$ plants but not in $\Delta \mathrm{C}_{514-530}$ plants (Figure $3 \mathrm{~B}$ ). Moreover, the use of another antibody, Anti-NRT2.1 19, targeting an epitope located in an internal loop (Figure 1), revealed that NRT2.1 protein is present at similar levels in PM of $\Delta \mathrm{C}_{494-530}$ and WT plants, which could not explained the reduction of HATS activity observed in $\Delta \mathrm{C}_{494-530}$ plants (Figure $3 \mathrm{~A})$. However, it is interesting to note that in $\Delta \mathrm{C}_{514-530}$ plants the level of NRT2.1 seems to be higher than in the WT and $\Delta \mathrm{C}_{494-530}$ plants (Figures $3 \mathrm{~A}$ and $3 \mathrm{~B}$ ). It suggests that the 514-530 C-terminal sequence is important for NRT2.1 stability in PM and acts in downregulating NRT2.1 protein accumulation in PM. However, this increase in NRT2.1 protein level in $\Delta \mathrm{C}_{514}$ 530 plants did not lead to an increase in root $\mathrm{NO}_{3}{ }^{-}$influx compared to the WT (Figure 2B).

Finally, to make sure that the interaction between NAR2.1 and NRT2.1 is not affected in $\Delta \mathrm{C}_{494-530}$ plants compared to $\Delta \mathrm{C}_{514-530}$ or WT plants, Blue native polyacrylamide gel electrophoresis (BN-PAGE) for NRT2.1 and NAR2.1 were performed using microsomes isolated from $\Delta \mathrm{C}_{514-530}$ and $\Delta \mathrm{C}_{494-530}$ plants induced by $1 \mathrm{mM} \mathrm{NO}_{3}{ }^{-}$for $4 \mathrm{~h}$. In control WT plants grown on $1 \mathrm{mM} \mathrm{NO}_{3}{ }^{-}$we found, as described previously (Yong et al., 2010), that NRT2.1 and NAR2.1 derived from the same protein complex (Figure 3C). However, in our case, the protein complex was approximately $400 \mathrm{kDa}$ while the one described by Yong et al. (2010) was smaller, around $150 \mathrm{kDa}$. As expected in plants $\Delta \mathrm{C}_{514-530}$, where NRT2.1 is active after an 
induction of $4 \mathrm{~h}$ on $1 \mathrm{mM} \mathrm{NO}_{3}^{-}$, the same $\sim 400 \mathrm{kDa}$ protein complex with NRT2.1 and NAR2.1 was found (Figure 3D). More surprisingly, this complex was also present in plants $\Delta \mathrm{C}_{494-530 \text {, }}$ where the NRT2.1/NAR2.1 complex is not active in those conditions, showing that the lack of activity is not due to a default of interaction between NRT2.1 and NAR2.1 (Figure 3E).

\section{Role of NRT2.1 phosphorylation in root $\mathrm{NO}_{3}^{-}$uptake activity}

The above data indicating a key role of the C-ter 494-513 sequence of NRT2.1 in determining root $\mathrm{NO}_{3}{ }^{-}$influx prompted us to make a parallel with data obtained from another approach aiming at investigating the tentative role of phosphorylation in the post-translational regulation of NRT2.1. Indeed, a mass spectrometry phosphoproteomic approach was taken to identify residues phosphorylated in vivo. Microsomes were isolated from WT and NRT2.1-GFP plants (Wirth et al., 2007) grown on $1 \mathrm{mM} \mathrm{NO}_{3}{ }^{-}$and harvested in the light. Phosphorylation sites were then identified with high-accuracy mass spectrometric phosphopeptide detection using an ion trap mass spectrometer Amazon Speed ETD (Figure 4A). Using this strategy 4 phospho-peptides were identified with 2 serines phosphorylated in NRT2.1 N-terminal part (S11 and S28) and 1 serine and 1 threonine phosphorylated in NRT2.1 C-terminal part (S501 and T521) (Figures 4A and 4B). Interestingly, the phosphorylation site S501 is located in the C-ter 494-513. We therefore decided to more specifically investigate if S501 phosphorylation could affect NRT2.1/NAR2.1 activity. To do so, transgenic lines were generated by expressing point S501 mutants of NRT2.1 in the nrt2.1-2 knock-out mutant under the control of the NRT2.1 promoter. In the mutant versions, the S501 residue was replaced by either an alanine (A) to generate a constitutively non-phosphorylable form or with an aspartic acid (D) to mimic a constitutively phosphorylated form.

Like for $\Delta \mathrm{C}_{514-530}$ and $\Delta \mathrm{C}_{494-530}$ plants, two independent transgenic lines (S501A7, S501A9 and S501D1, S501D2) for each construct were selected, based on the correct expression and regulation of the transgenes in response to $\mathrm{NO}_{3}{ }^{-}$induction compared to WT plants (Figure $5 \mathrm{C}$ ). Again, strikingly, the same growth deficiency phenotype as for $\Delta \mathrm{C}_{494-530}$ plants was observed for S501D plants, while the growth of S501A plants was similar to the WT when plants were grown on $1 \mathrm{mM} \mathrm{NO}_{3}{ }^{-}$(Figure 5A). It suggested that mimicking the constitutive phosphorylation of S501 residue could resume, on its own, the phenotype observed in $\Delta \mathrm{C}_{494-530}$ plants, when the peptide containing this residue was truncated. Accordingly, $\mathrm{NO}_{3}^{-}$HATS activity measurements, performed in the same conditions as described above, confirmed that the S501D substitution also prevents the induction of root $\mathrm{NO}_{3}{ }^{-}$influx in response to $\mathrm{NO}_{3}^{-}$, just like in 
$\Delta \mathrm{C}_{494-530}$ plants, while the $\mathrm{S} 501 \mathrm{~A}$ substitution leads to the same level of root $\mathrm{NO}_{3}{ }^{-}$influx as in WT plants (Figure 5B). Since in all the genotypes the level of NAR2.1 expression was the same as in the WT and that NRT2.1 expression was normally induced by $\mathrm{NO}_{3}{ }^{-}$in both $\mathrm{S} 501 \mathrm{~A}$ and S501D plants compared to WT, default of HATS activity in S501D plants could not be explained by a default in the expression of NRT2.1 or NAR2.1 (Figures 5C and 5D). Furthermore, like in $\Delta \mathrm{C}_{494-530}$ plants, the lack of root $\mathrm{NO}_{3}{ }^{-}$influx due to the S501D substitution was not specific of the regulation by $\mathrm{NO}_{3}{ }^{-}$and was also observed in response to high $\mathrm{N}$, light and sugar (Supplemental Figures 1C and 1D). These results indicate that phosphorylation of the S501 residue has a general impact on NRT2.1 activity independently of the environmental conditions.

Western blots and BN PAGE were then performed, using respectively PM and microsomes isolated from plants starved for $\mathrm{N}$ during 5 days and induced by $1 \mathrm{mM} \mathrm{NO}_{3}^{-}$during $4 \mathrm{~h}$. The results showed that both NAR2.1 and NRT2.1 proteins are present in all the genotypes. However, the amount of NRT2.1 protein seems to be lower in S501D plants compared to S501A and WT plants (Figures 6A and 6B). It is interesting to note that this result was obtained with both antibodies Anti-NRT2.1 (19) and (20), suggesting that this lower level of NRT2.1 in S501D plants was not due to any processing of NRT2.1 C-terminal part because of the mutation. Nevertheless, this cannot fully explain, the total lack of NRT2.1 activity in S501D plants. Indeed, $\mathrm{NO}_{3}{ }^{-}$still markedly increases the level of NRT2.1 protein in those plants and should have led to a higher increase in root $\mathrm{NO}_{3}{ }^{-}$influx than in the $n r t 2.1-2$ mutant, which was not observed. Furthermore, BN PAGE indicates that the S501D substitution has no impact on the NRT2.1/NAR2.1 protein complex, which is still found at $400 \mathrm{kDa}$ in both S501A and S501D plants (Figures 6C and 6D). In this case, the normal interaction between NRT2.1 and NAR2.1 was also confirmed by $\mathrm{rBiFC}$ experiments performed on tobacco leaves (Figure 6E and Supplemental Figure 2). The quantification of the fluorescence signal shows that when the leaves are transformed with the WT forms of NAR2.1 and NRT2.1, YFP fluorescence is about $40 \%$ of the control RFP fluorescence, while in the leaves transformed with both NAR2.1 and NRT2.1 S501A or S501D mutated forms, YFP fluorescence is even slightly higher than with the WT form, with an YFP fluorescence of around 50\% of RFP fluorescence (Figure 6E). It clearly confirms that the lack of activity of NRT2.1 S501D mutated form can be explained neither solely by a decrease in NRT2.1 or NAR2.1 protein level nor by a default of interaction between NRT2.1 and NAR2.1 in the same protein complex as the one observed in WT and in S501A plants. 


\section{Regulation of S501 phosphorylation in WT plants}

The phenotype of the S501D plants suggests that the phosphorylation of the S501 residue may correspond to a major regulatory mechanism able to inactivate the NRT2.1/NAR2.1 transport system. This raised the question of whether this phosphorylation actually occurs in vivo, especially when the HATS activity is modulated in response to environmental conditions. To follow the level of S501 phosphorylation in WT plants, two specific polyclonal antibodies, called Anti-S501P and Non-specific NRT2.1 antibody, were raised in rabbit against a NRT2.1 S501 phosphopeptide and its non-phosphorylated counterpart, respectively. The affinitypurified anti-NRT2.1 antibodies were tested with dot-blots using the synthetic peptides produced to purify the antibodies. It confirmed that Anti-S501P antibody could only recognize S501 phosphorylated peptide while NRT2.1 non-specific antibody recognized both S501 phosphorylated and non-phosphorylated peptides (Supplemental Figure 3).

To follow the level of S501 phosphorylation, WT plants were first, as described above, starved for $\mathrm{N}$ for 5 days and then transferred on $1 \mathrm{mM} \mathrm{NO}_{3}{ }^{-}$during $4 \mathrm{~h}$. However, in those conditions, the amount of NRT2.1 after 5 days on $0 \mathrm{~N}$ was too low to allow detection of the phosphorylated form of NRT2.1 with anti-S501P antibody using either microsomes or PM (data not shown). In order to follow the impact of $\mathrm{NO}_{3}{ }^{-}$induction on $\mathrm{S} 501$ phosphorylation, microsomes were thus isolated from plants induced during $1 \mathrm{~h}$ or $4 \mathrm{~h}$ with $1 \mathrm{mM} \mathrm{NO}_{3}{ }^{-}$after 5 days of $\mathrm{N}$ starvation. In those conditions, root $\mathrm{NO}_{3}{ }^{-}$influx was still induced about 2-fold between $1 \mathrm{~h}$ and $4 \mathrm{~h}$ in WT plants compared to nrt2.1-2 mutant, and the level of NRT2.1 was already high enough at $1 \mathrm{~h}$ to allow the phosphorylated form to be detected with S501 specific antibody (Supplemental Figures 4 and 7). Quantitative analysis by ELISA, using both antiS501P and anti-NRT2.1-20 antibodies, revealed that, after $4 \mathrm{~h}$ of $\mathrm{NO}_{3}{ }^{-}$re-supply, the overall level of NRT2.1 protein increased, while the level of NRT2.1 S501 phosphorylated form did not change compared to plants re-supplied with $\mathrm{NO}_{3}^{-}$for $1 \mathrm{~h}$ (Figure 7B). This result is consistent with a role of S501 phosphorylation in NRT2.1 inactivation as it indicates that the level of S501 phosphorylation in WT plants decreases in conditions where NRT2.1 becomes more active. But surprisingly, when western blots were performed on the same experiments, the abundance of the band corresponding to NRT2.1 at $\sim 45 \mathrm{kDa}$ increased both after detection with anti-S501P and anti-NRT2.1-20 antibodies, which did not correspond to the quantitative results obtained with ELISA (Figure 7A). However, as described in Wirth et al. (2007) when using microsomes, two other bands, at $\sim 100 \mathrm{kDa}$ and $\sim 130 \mathrm{kDa}$, corresponding presumably to NRT2.1 multimeric forms, were detected with both antibodies. The use of nrt2.1-2 knock- 
out mutant confirmed that all the bands were specific for NRT2.1 protein with both anti-S501P and anti-NRT2.1-20 antibodies. Interestingly, NRT2.1 S501 phosphorylated form was more abundant in the high molecular mass bands after $1 \mathrm{~h}$ of $\mathrm{NO}_{3}{ }^{-}$re-supply compared to $4 \mathrm{~h}$, while in the same samples the level of total NRT2.1 protein in the high molecular mass bands was not affected or even slightly increased after $4 \mathrm{~h}$ of $\mathrm{NO}_{3}{ }^{-}$re-supply compared to $1 \mathrm{~h}$ (Figure $7 \mathrm{~A}$ ). These results suggest that the apparent increase of the band at $\sim 45 \mathrm{kDa}$, for the S501 phosphorylated fraction of NRT2.1, was not due to an increase in the amount of NRT2.1 phosphorylated form in response to $\mathrm{NO}_{3}{ }^{-}$but rather to a removal of the phosphorylated form of NRT2.1 from the multimeric forms of NRT2.1 in response to $\mathrm{NO}_{3}{ }^{-}$. In the same time, it means that the increase in total NRT2.1 protein, detected with anti-NRT2.1 20 after 4h of $\mathrm{NO}_{3}^{-}$resupply, corresponds mainly to an increase in NRT2.1 non phosphorylated on S501, which becomes the main form in the high molecular mass band after $4 \mathrm{~h}$ of $\mathrm{NO}_{3}{ }^{-}$re-supply compared to $1 \mathrm{~h}$ (Figures 7A and 7B).

\section{Impact of S501 mutation on root development}

Previous studies showed that, independently of its role in root $\mathrm{NO}_{3}{ }^{-}$uptake, NRT2.1 is involved in lateral root (LR) development (Little et al., 2005; Remans et al., 2006). It leads to the hypothesis that, like NRT1.1, NRT2.1 could be a $\mathrm{NO}_{3}^{-}$sensor (Krouk et al., 2010). However, the mechanism involved remains completely unknown and a key evidence to support a role for NRT2.1 in $\mathrm{NO}_{3}{ }^{-}$sensing would be to uncouple its activity as a root $\mathrm{NO}_{3}{ }^{-}$transporter from its role in LR development. Since the S501D substitution was able to inactivate NRT2.1 as a $\mathrm{NO}_{3}{ }^{-}$transporter, it prompted us to investigate its impact on lateral root development. To determine whether lateral root development is affected by S501 phosphorylation, the total numbers of initiated LR primordia and visible LRs were scored in the newly formed portion of the primary root in WT, atnrt2.1-2, S501A and S501D plants after transfer from $1 \mathrm{mM} \mathrm{NO}_{3}^{-}$to $0 \mathrm{~N}, 0.3 \mathrm{mM} \mathrm{NO}_{3}^{-}$or $5 \mathrm{mM} \mathrm{NO}_{3}^{-}$(Figure 8).

As described in Remans et al. (2006), KO mutation of NRT2.1 resulted in a reduced LR initiation in the portion of the primary root developing after transfer to $\mathrm{N}$-free medium or to the $0.3 \mathrm{mM} \mathrm{NO}_{3}{ }^{-}$medium as compared to WT (Figure 8). This difference between the two genotypes was not observed after transfer to the $5 \mathrm{mM} \mathrm{NO}_{3}{ }^{-}$medium, confirming that mutation of NRT2.1 has no significant consequence on LR growth under non-limiting $\mathrm{N}$ supply (Orsel et al., 2004; Little et al., 2005; Remans et al., 2006). S501D plants had the same phenotype than nrt2.1-2 knock-out plants, with a similar decrease in the density of initiated LR primordia after 
transfer to $0 \mathrm{~N}$ and $0.3 \mathrm{mM} \mathrm{NO}_{3}{ }^{-}$and no significant difference on $5 \mathrm{mM} \mathrm{NO}_{3}{ }^{-}$compared to the WT (Figure 8). Conversely, the density of initiated LR primordia in S501A plants was similar to the WT in all the conditions. These data confirm that NRT2.1 acts as an activator of LR primordia initiation, even when its substrate is absent. They also clearly indicate that the S501D substitution is able to inactivate both NRT2.1 root $\mathrm{NO}_{3}{ }^{-}$uptake activity and its role in LR development under limiting $\mathrm{N}$ supply, whereas the S501A substitution did not affect both NRT2.1 functions.

\section{Discussion}

\section{Role of NRT2.1 phosphorylation in root $\mathrm{NO}_{3}^{-}$uptake activity}

In previous studies we provided evidence for post-translational regulations of the root NRT2.1/NAR2.1 $\mathrm{NO}_{3}^{-}$transporter (Wirth et al., 2007; Laugier et al., 2012). One of the hypotheses was that NRT2.1 C-terminus was cleaved and that this mechanism could play a role in the regulation of NRT2.1 activity (Wirth et al., 2007). The results obtained with truncated forms of NRT2.1 show that $\Delta \mathrm{C}_{494-530}$ plants have the same phenotype than $n r t 2.1-2$ knock-out mutant for growth and root $\mathrm{NO}_{3}{ }^{-}$influx, while $\Delta \mathrm{C}_{514-530}$ plants are like the wild-type (Figure 2). It thus seems at first sight to support the hypothesis that partial proteolysis of NRT2.1 Cterminus sequence may play a role in NRT2.1 activity. However, the characterization of NRT2.1 phosphorylation sites provides a different explanation for the phenotype observed in $\Delta \mathrm{C}_{494-530}$ plants. We found 4 phosphorylated residues in NRT2.1: S11, S28, S501 and T521 (Figure 4). These results are consistent with previous studies showing that S11, S28 and T521 are phosphorylated under $\mathrm{NO}_{3}{ }^{-}$conditions (Engelsberger and Schulze, 2012; Menz et al., 2016), but to our knowledge, this is the first time that S501 was found to be phosphorylated. Interestingly, S501 is also the only phosphorylation site identified in the C-terminus part of NRT2.1, which we found to be strictly required for $\mathrm{NO}_{3}{ }^{-} \mathrm{HATS}$ activity. The phenotype of the transgenic plants we produced with NRT2.1 S501 point mutants strikingly revealed that mimicking the constitutive phosphorylation in S501D plants is able to resume the phenotype observed in $\Delta \mathrm{C}_{494-530}$ plants (Figure 5). It indicates that the impact of NRT2.1 $\Delta \mathrm{C}_{494-530}$ deletion on root $\mathrm{NO}_{3}{ }^{-}$uptake activity is not directly due to the lack of the deleted sequence but rather to the fact that the deletion in $\Delta \mathrm{C}_{494-530}$ plants removes $\mathrm{S} 501$ phosphorylation site, while it remains intact in $\Delta \mathrm{C}_{514-530}$ plants. Indeed, the phenotype of S501D plants cannot be explained by any NRT2.1 C-terminus processing due to the substitution since NRT2.1 can still be detected in 
Western blots by the antibody NRT2.120, which targets an epitope localized specifically in the truncated part responsible for NRT2.1 inactivation in $\Delta \mathrm{C}_{494-530}$ plants (Figures 6A and 6B).

Furthermore, the fact that S501A has the same phenotype as wild type plants indicates that S501 phosphorylation is likely involved in NRT2.1 inactivation, while S501 dephosphorylation enables NRT2.1 activation. It is also interesting to note that the loss of NRT2.1 activity in S501D plants is not only observed in response to $\mathrm{NO}_{3}{ }^{-}$induction. Indeed, the lack of root $\mathrm{NO}_{3}{ }^{-}$ uptake activity in $\Delta \mathrm{C}_{494-530}$ and $\mathrm{S} 501 \mathrm{D}$ plants is also observed in response to induction by light and sugar and repression by $10 \mathrm{mM} \mathrm{NH}_{4} \mathrm{NO}_{3}$ (Supplemental Figure 1). It supports the hypothesis that the absence of phosphorylation of NRT2.1 S501 residue is required for NRT2.1 activity and that it cannot be overcome by any other post-translational modifications potentially triggered by other environmental factors.

\section{Characterization of the mechanisms involved in NRT2.1 inactivation}

Since phosphorylation can induce changes in protein activity (Liu and Tsay, 2003), provide docking sites for protein-protein interaction (Pawson and Scott, 1997) or induce changes in subcellular localization (Navarro et al., 2008), we tested the impact of S501 mutations on those different aspects in order to further characterize the mechanisms involved in NRT2.1 inactivation.

The fact that NRT2.1 is still detected in $\Delta \mathrm{C}_{494-530}$ or S501D plants, when western blots are performed with purified plasma membrane fractions, ruled out the hypothesis that the complete lack of NRT2.1 activity in those plants is due to changes in its subcellular location compared to WT plants (Figures 3A, 3B, 6A and 6B).

Protein-protein interaction is a known mechanism for NRT2.1 since it requires a second protein, NAR2.1 (Okamoto et al., 2006; Orsel et al., 2006), to generate a heterooligomer that may be the active form of the transporter (Yong et al., 2010). However, to date, the mechanism remains unknown and S501 phosphorylation could prevent NRT2.1 transport activity by disrupting NRT2.1 and NAR2.1 interaction. Therefore, we performed BN-PAGE and rBiFC experiments to test the interaction between NAR2.1 and NRT2.1 S501A and S501D mutated forms compared to WT form (Figures 6C, 6D and 6E). The data show that, even when NRT2.1 is inactive in S501D plants, the mutation does not change the size of the protein complex at $480 \mathrm{kDa}$ nor the interaction with NAR2.1 inside this complex. These results indicate that S501 phosphorylation does not prevent NRT2.1 interaction with NAR2.1 to explain the loss of NRT2.1 activity in S501D plants compared to S501A and WT plants. This conclusion is 
supported by the BN-PAGE experiments performed with the truncated forms of NRT2.1 Cterminus part (Figures 3C, 3D and 3E). Indeed, the size of the complex at $\sim 480 \mathrm{kDa}$ and the presence of NAR2. 1 in this complex is the same in $\Delta \mathrm{C}_{494-530}$ plants, where NRT2.1 is not active, compared to $\Delta \mathrm{C}_{514-530}$ and WT plants, where NRT2.1 is active. It confirms that neither S501 phosphorylation states nor NRT2.1 C-terminus region, from at least the amino acids 493 to 530, can provide a docking site for NAR2.1 interaction. The conclusion that NRT2.1 C-terminus is not involved in the interaction with NAR2.1 is supported by the recent yeast two-hybrid (Y2H) experiments performed by Kotur et al. (2017). In this work, the authors identified a leucine residue located in the first putative trans-membrane region at position 85 of NRT2.1, which when mutated to glutamine resulted in disruption of the interaction between NAR2.1 and NRT2.1. Finally, it has been shown previously that in the nar2.1 mutants, NRT2.1 protein is absent although mRNA encoding NRT2.1 is present (Wirth et al., 2007; Yong et al., 2010). It leads to the hypothesis that, unless NAR2.1 is available to generate the NAR2.1/NRT2.1 complex, the NRT2.1 protein is degraded. Thus, if NRT2.1/NAR2.1 interaction was affected in $\Delta \mathrm{C}_{494-530}$ and S501D plants, we should have observed an absence of NRT2.1 protein in those plants.

If disruption of protein-protein interaction between NRT2.1 and NAR2.1 cannot explain the phenotype of $\Delta \mathrm{C}_{494-530}$ and S501D plants, it cannot be ruled out that the removal of NRT2.1 Cterminus containing $\mathrm{S} 501$, in $\Delta \mathrm{C}_{494-530}$ plants, or S501D substitution are able to prevent interaction with other unknown partner proteins involved in NRT2.1 activity. Indeed, the protein complex we detect is very large $(\sim 480 \mathrm{kDa})$ and could contain several subunits of NRT2.1 and NAR2.1 associated with other proteins. In Yong et al. (2010) however, the authors found a protein complex of only $\sim 150 \mathrm{kDa}$, that they explained by the interaction of two subunits each of NRT2.1 and NAR2.1. The reason for this discrepancy in the size of the protein complex between our results and theirs are not clear. Perhaps the buffers and/or conditions used for isolation of microsomes/plasma membranes and/or BN-PAGE slightly differ between our two laboratories leading to partial denaturation of a bigger NRT2.1/NAR2.1 protein complex in Yong et al. (2010) conditions. More denaturing conditions could also explain why Yong et al. (2010) do not detect any anti-NRT2.1 reactive polypeptides at approximately 75 and 120 $\mathrm{kDA}$ in regular Western-blots as it was found by Wirth et al. (2007). This would support the hypothesis of a core complex constituted of two or more subunits each of NRT2.1 and NAR2.1 associated with one or several proteins, which could be more sensitive to partial denaturation depending on the strength of their interactions with NRT2.1 and/or NAR2.1. 


\section{S501 phosphorylation in wild-type plants}

The results obtained with the transgenic plants expressing NRT2.1 S501 point mutants raised the question of the regulation of S501 phosphorylation in wild-type plants. If mimicking constitutive phosphorylation of S501 leads to inactivation of NRT2.1, one would expect that in wild-type plants, NRT2.1 S501 residue is phosphorylated in conditions where NRT2.1 is not active and not phosphorylated when plants are transferred in conditions where NRT2.1 is activated. In Arabidopsis, inactivation of a transporter through phosphorylation of the Cterminus part of the protein has already been demonstrated for the ammonium transporter AMT1.1 (Loque et al., 2007). Indeed, AMT1.1 in plants, like MEP2 in yeast, works as a trimer, which activity is controlled by the spatial positioning of the C-terminus. When ammonium is added in the growth medium, it triggers rapid phosphorylation of a conserved threonine residue (T460) in the C-terminus of AMT1.1 in a time- and concentration-dependent manner (Loque et al., 2007; Lanquar et al., 2009). This phosphorylation of T460 in response to an increase in external ammonium correlates with a reduction of ammonium uptake activity in roots. These results lead to a model in which T460 phosphorylation induces a conformational change and that a single phosphorylation event in the C-terminus of one monomer is sufficient for cooperative closure of the trimer (Lanquar et al., 2009; Lanquar and Frommer, 2010).

For NRT2.1, the ELISA data show that NRT2.1 S501 phosphorylated form is relatively less abundant compared to NRT2.1 unphosphorylated form after $4 \mathrm{~h}$ of $\mathrm{NO}_{3}{ }^{-}$re-supply (Figure 7B). It correlates with an induction of root $\mathrm{NO}_{3}{ }^{-}$uptake activity in the same experiment (Supplemental Figure 4) and thus support the hypothesis that when $\mathrm{NO}_{3}^{-}$is added in the medium, it triggers S501 de-phosphorylation, which activates NRT2.1. However, ELISA experiments also show that the level of NRT2.1 protein increases about 2.5 fold after $4 \mathrm{~h}$ of $\mathrm{NO}_{3}{ }^{-}$induction compared to $1 \mathrm{~h}$, while in the same time the amount of NRT2.1 S501 phosphorylated form is not affected by $\mathrm{NO}_{3}{ }^{-}$re-supply. It suggests that in fact, $\mathrm{NO}_{3}{ }^{-}$does not activate NRT2.1 de-phosphorylation but rather induces synthesis of new unphosphorylated NRT2.1 protein. Furthermore, compared to studies on ammonium, the kinetics of root $\mathrm{NO}_{3}{ }^{-}$ uptake induction after $\mathrm{NO}_{3}{ }^{-}$re-supply is rather slow. Indeed, when $\mathrm{N}$-deficient Arabidopsis plants are resupplied with ammonium, ammonium influx into roots is repressed within minutes (Rawat et al., 1999), while it takes several hours for root $\mathrm{NO}_{3}{ }^{-}$uptake to be induced after $\mathrm{NO}_{3}{ }^{-}$ resupply (Supplemental Figure 4) (Cerezo et al., 2001). These data also support the idea that NRT2.1 activation after $\mathrm{NO}_{3}{ }^{-}$resupply is not due to rapid S501 dephosphorylation. 
The Western blots we performed on the same samples used for ELISA revealed an even more complex picture. Indeed, both the level of NRT2.1 and NRT2.1 S501 phosphorylated form, detected at $\sim 45 \mathrm{kDa}$, were induced after $4 \mathrm{~h}$ of $\mathrm{NO}_{3}{ }^{-}$resupply compared to $1 \mathrm{~h}$ (Figure 7A). This result was very surprising since it did not reconcile with the ELISA experiments showing only an increase of NRT2.1 protein level after $4 \mathrm{~h}$ of $\mathrm{NO}_{3}{ }^{-}$resupply and not of the phosphorylated form (Figure 7B). However, when increasing the exposure time of the membranes, we were able to detect with both S501-P and NRT2.1-20 antibodies two other bands with a higher molecular weight at $\sim 100 \mathrm{kDa}$ and $\sim 150 \mathrm{kDa}$. These bands have already been described by Wirth et al. (2007) as specific of NRT2.1 and as revealing higher molecular mass complexes incorporating NRT2.1. The fact that NRT2.1 is part of a high molecular weight complex together with NAR2.1 has been confirmed in this study and by Yong et al. (2010), even if as discussed above the size found for this complex can vary. In our case, the bands at $100 \mathrm{kDa}$ and $\sim 150 \mathrm{kDa}$ in Western-blots could thus correspond to incomplete denaturation of the protein complex at $\sim 480 \mathrm{kDa}$ detected when doing BN-PAGE and/or residual disulfide bonding between two or three NRT2.1 monomers and/or other proteins different from NAR2.1. Indeed, in all the experiments we performed, NAR2.1 antibody failed to detect any band at $100 \mathrm{kDa}$ and $\sim 150 \mathrm{kDa}$ in Western blot (data not shown). Interestingly, the detection of these higher molecular weight bands revealed that the activation of NRT2.1 after $4 \mathrm{~h}$ of $\mathrm{NO}_{3}^{-}$resupply seems to be associated with the removal of NRT2.1 S501 phosphorylated form from the complex at $\sim 150 \mathrm{kDa}$ and its appearance as a monomeric form at $\sim 45 \mathrm{kDa}$ (Figure 7A). It explains why no apparent changes in the level of the overall NRT2.1501 phosphorylated form was detected in ELISA (Figure 7B) and it reinforces our hypothesis that NRT2.1 activation is due to the synthesis of new unphosphorylated NRT2.1 protein and not to S501 dephosphorylation. Furthermore, it suggests that NRT2.1 activity depends on the composition of the high molecular weight complex, which would mainly contain NRT2.1 S501 phosphorylated form when it is inactive and the newly synthetized unphosphorylated form of NRT2.1 when it becomes active.

Considered together these results are consistent with a model (Figure 9) in which, (i) under no N conditions, NRT2.1 is phosphorylated on S501 residue and lead to the inactivation of a protein complex composed of several subunits of each NAR2.1 and NRT2.1 phosphorylated form, maybe associated with other unknown proteins and (ii) after addition of $\mathrm{NO}_{3}{ }^{-}, \mathrm{NRT} 2.1$ synthesis is induced and S501 phosphorylation is inhibited, leading to the activation of a protein 
complex composed of several subunits of each NAR2.1 and newly synthetized NRT2.1 unphosphorylated form, maybe associated with other unknown proteins.

\section{Impact of NRT2.1 S501 phosphorylation on root development}

Beyond the role of NRT2.1 in root $\mathrm{NO}_{3}^{-}$uptake there are some indications that NRT2.1 could also act as a $\mathrm{NO}_{3}{ }^{-}$sensor to coordinate the development of the root system with $\mathrm{NO}_{3}{ }^{-}$ availability. The first indication comes from a genetic screen, which isolated the lin 1 mutant resistant to the repressive effect of a high sucrose $/ \mathrm{NO}_{3}{ }^{-}$ratio on LR initiation (Malamy and Ryan, 2001). The lin 1 mutant was found to carry a missense mutation in NRT2.1 and indicates that NRT2.1 acts as a repressor of LR initiation under high sucrose/low $\mathrm{NO}_{3}{ }^{-}$supply (Little et al., 2005). The second indication comes from Remans et al. (2006), who also found a LR initiation phenotype for a nrt2.1 mutant. However, in this study, nrt2.1 plants initiated less LR primordia than the wild type under $\mathrm{NO}_{3}{ }^{-}$limited condition suggesting an activator role for NRT2.1 in LR initiation. Despite these discrepancies, LR initiation phenotype of the nrt2.1 mutants is observed in both studies even in the absence of added $\mathrm{NO}_{3}{ }^{-}$in the external medium. Altogether, these data show that NRT2.1 seems to fulfill a dual transport/signaling role, thus displaying functional properties of a putative transceptor like for example the ammonium transporter MEP2 in yeast or the $\mathrm{NO}_{3}{ }^{-}$transporter NRT1.1 in Arabidopsis (Lorenz and Heitman, 1998; Ho et al., 2009; Krouk et al., 2010).

One of the most convincing evidence for a membrane transporter to act as a transceptor is the genetic uncoupling of transport function and signaling effects. For example, under conditions of nitrogen limitation, MEP2 initiates a signaling cascade that triggers filamentous (pseudohyphal) growth of the yeast colonies. This response can be uncoupled from the ammonium transport function of MEP2 by point mutations within the central loop of the protein (Van Nuland et al., 2006). For NRT1.1, a point mutation, P492L, uncouples transport and sensing and in the corresponding mutant plant (chll-9), transport is impaired, while the sensing function, namely the induction of NRT2.1 expression, is still functional (Ho et al., 2009). For NRT2.1, our data show that S501D substitution does not allow uncoupling the transport function from the signaling effect. Indeed, S501D plants are impaired for root $\mathrm{NO}_{3}{ }^{-}$uptake and have the same defect in LR initiation than nrt2.1 mutant under low $\mathrm{NO}_{3}{ }^{-}$conditions, while S501A plants behave like the WT for both $\mathrm{NO}_{3}{ }^{-}$uptake and root development (Figure 8). It indicates that S501 phosphorylation does not directs the action of NRT2.1 towards the activation of specific responses. Since the defect in LR initiation in S501D plants is also 
observed on a $\mathrm{N}$-free medium, it confirms, as described previously, that the signaling mechanism cannot be explained by a lack of NRT2.1 capacity to transport $\mathrm{NO}_{3}{ }^{-}$(Little et al., 2005; Remans et al., 2006). Furthermore, it suggests that NRT2.1 signaling mechanism does not depend on the presence or absence of the protein since the same decrease in LR initiation is observed in both nrt2.1 mutant and S501D plants (Figure 8). However, the mechanisms involved remain unknown and will require further investigation to elucidate the role of S501 phosphorylation in NRT2.1 $\mathrm{NO}_{3}{ }^{-}$uptake activity and signaling for LR development.

\section{Conservation of NRT2.1 S501 phosphorylation site across plant species}

A major role of S501 phosphorylation site for NRT2.1 activity is also supported by the fact that this residue is very strongly conserved in all Arabidopsis ecotypes (data not shown) and in all plant species where a clear NRT2.1 homolog has been identified (Figure 10). The alignment of NRT2.1 C-terminus reveals that except in yeast and fungus, the serine corresponding to S501 in Arabidopsis is remarkably conserved across most algae, mosses, dicotyledons and monocotyledons. The fact that S501 does not align with NRT2.1 homologs from fungus and yeast corresponds to previous models for the membrane topology of these polypeptides showing that NRT2.1 C-terminal extension is a general feature of NRT2 transporters from algae and higher plants, which is absent in yeast and fungus (Forde, 2000; Jacquot et al., 2017). However, more surprisingly, the serine corresponding to S501 in Arabidopsis is also noticeably replaced by a glycine in the three monocotyledons wheat (Triticum aestivum), barley (Hordeum vulgare) and Brachypodium distachyon, while it is conserved in rice for example (Oryza sativa). If there is for now no elements to explain this discrepancy between these three species and the other plants, it is interesting to note that such specificity for barley has already been observed for another residue, Ser463. Indeed, this residue also located in the C-terminus of HvNRT2.1, has been shown to be required for the interaction between HvNRT2.1 and HvNAR2.1 (Ishikawa et al., 2009). However, this residue is only conserved in NRT2.1 transporters from algae and monocotyledons, but not in dicotyledons (Jacquot et al., 2017). These discrepancies between essential amino acids for either NRT2.1 activity and/or interaction with partner proteins among different plant species, could reveal the existence of several molecular mechanisms for the regulation of NRT2.1 at the post-translational level. It seems to be at least already the case for the interaction between NAR2.1/NRT2.1, which appears to involve the C-terminus part of NRT2.1 for barley (Ishikawa et al., 2009) instead of the Nterminus part of NRT2.1 in Arabidopsis (Kotur et al., 2017). 


\section{Methods}

\section{Generation of transformant lines}

All constructs were made using Gateway technology (Invitrogen) according to the manufacturer's instructions. For the truncated forms of NRT2.1, the NRT2.1 DNA sequence from the bac clone T6D22 (ARBC, Columbus, OH), including the 1335-bp 5' untranslated region and promoting sequence upstream the ATG, was amplified using the primers: NRT2.1 GATE forward 5'-CACCCACGTCAGCGAGATTGATCG-3'; NRT2.1 SANS reverse : 5' TCACTGCTTCTCCTGCTCATTCCACTC 3' ( $\Delta \mathrm{C}_{494-530}$ plants $)$ or NRT2.1 AVEC reverse : 5' TCAGCGTCCACCCTCTGACTTGGCGTT $3^{\prime}$ ( $\Delta \mathrm{C}_{514-530}$ plants $)$. For site directed mutagenesis the NRT2.1 DNA sequence from the bac clone T6D22 was amplified using: NRT2.1 GATE forward 5'-CACCCACGTCAGCGAGATTGATCG-3'; GATE NRT2.1 R, 5'TCAAACATTGTTGGGTGTGTT-3'. Each amplification was cloned into the pENTR ${ }^{\mathrm{TM}} / \mathrm{D}-$ Topo vector (Invitrogen) to create entry clones. For site directed mutagenesis, NRT2.1 mutations were introduced by PCR of the whole entry clone with primers pair containing the desired site-directed mutation (NRT2.1 S501A Fw 5'GAACATGCATCAAGGAGCTCTCCGGTTTGCCGAG-3', NRT2.1 S501A Rev 5'CTCGGCAAACCGGAGAGCTCCTTGATGCATGTTC-3'; NRT2.1 S501D Fw 5'GAACATGCATCAAGGAGATCTCCGGTTTGCCGAG-3', NRT2.1 S501D Rev 5'CTCGGCAAACCGGAGATCTCCTTGATGCATGTTC-3'). After transformation of MacCell $^{\mathrm{TM}} \mathrm{DH} 5 \alpha 10^{9}$ thermocompetent Escherichia coli (iNtRON Biotechnology), clones were fully sequenced before subsequent cloning in the binary Gateway destination vector pGWB501 obtained from Tsuyoshi Nakagawa (Research Institute of Molecular Genetics, Shimane University, Matsue, Japan) by using a Gateway LR Clonase enzyme mix (Invitrogen). The binary construct was introduced into the Agrobacterium tumefaciens strain GV3101, and the resulting bacterial culture was used to transform the atnrt2.1-2 mutant plants, ecotype Col0, by the standard flower dip method (Clough and Bent, 1998). The transformants were selected on a medium containing hygromycin $\left(25 \mu \mathrm{g} \cdot \mathrm{mL}^{-1}\right)$. For further analyses, T1 segregation ratios were analyzed to select transformants with one T-DNA insertion and to isolate T3-homozygous plants. 


\section{Growth conditions}

Plants were grown hydroponically using the experimental set-up described previously (Lejay et al., 1999). Briefly, seeds were sown directly on the surface of wet sand in modified 1.5-ml microcentrifuge tubes, with the bottom replaced by a metal screen. The tubes supporting the seeds were placed on polystyrene floating rafts, on the surface of a 10-liter tank filled with tap water. The culture was then performed in a controlled growth chamber with $8 \mathrm{H} / 16 \mathrm{H}$ day/night cycle at $23 / 20{ }^{\circ} \mathrm{C}$ and $\mathrm{RH}$ of $65 \%$. Light intensity during the light period was at $250 \mu \mathrm{mol} . \mathrm{m}^{-}$ ${ }^{2} \cdot \mathrm{s}^{-1}$. One week after sowing, the tap water was replaced by nutrient solution until the age of 57 weeks depending on the size of the plants. The basal nutrient solutions supplied to the plants are those described by (Gansel et al., 2001) and contained either $1 \mathrm{mM} \mathrm{NO}_{3}{ }^{-}$or $10 \mathrm{mM} \mathrm{NH}_{4} \mathrm{NO}_{3}$ as nitrogen sources. The nutrient solution was replaced every week during this period and the day before the experiment. For $\mathrm{NO}_{3}{ }^{-}$induction experiments, plants grown on $1 \mathrm{mM} \mathrm{NO}_{3}{ }^{-}$were transferred during 5 days on a $\mathrm{N}$-free solution before the experiment.

For root architecture analysis, the plants were grown in vertical agar plates on a $1 \mathrm{mM} \mathrm{NO}_{3}^{-}$ in vitro culture as described in Remans et al. (2006). The culture was performed in a controlled growth chamber with $16 \mathrm{H} / 8 \mathrm{H}$ day/night cycle at $20 / 20{ }^{\circ} \mathrm{C}$ and $\mathrm{RH}$ of $70 \%$. Light intensity during the light period was at $250 \mu \mathrm{mol} . \mathrm{m}^{-2} \cdot \mathrm{s}^{-1}$. After 6 days of development, the seedlings were transferred to $0 \mathrm{mM} \mathrm{NO}_{3}^{-}, 0.3 \mathrm{mM} \mathrm{NO}_{3}^{-}(\mathrm{LN})$ or $5 \mathrm{mM} \mathrm{NO}_{3}^{-}(\mathrm{HN})$. The plants were then harvested after 7 days of development. Length measurements of the main root were performed on the Fiji ${ }^{\circledR}$ software. Quantification of primordia was performed with an OLYMPUS BH2 microscope. The average density of primordia was obtained in relation to the size of the primary root.

\section{RNA Extraction and Gene Expression Analysis}

Root samples were frozen in liquid $\mathrm{N}_{2}$ in 2-mL tubes containing one steel bead $(2.5 \mathrm{~mm}$ diameter). Tissues were disrupted for $1 \mathrm{~min}$ at $28 \mathrm{~s}^{-1}$ in a Retsch mixer mill MM301 homogenizer (Retsch, Haan, Germany). Total RNA was extracted from tissues using TRIzol reagent (Invitrogen, Carlsbad, CA, USA). Subsequently, $4 \mu \mathrm{g}$ of RNAs were treated with DNase (DNase I Amplification Grade, Sigma) following the manufacturer's instructions. Reverse transcription was achieved with $4 \mu \mathrm{g}$ of RNAs in the presence of Moloney Murine Leukemia Virus (M-MLV) reverse transcriptase, (RNase H minus, Point Mutant, Promega) after annealing with an anchored oligo(dT) 18 primer as described by Wirth et al. (2007). The 
quality of the cDNA was verified by PCR using specific primers spanning an intron in the gene APTR (Atlg27450) forward 5'- CGCTTCTTCTCGACACTGAG-3'; reverse 5'CAGGTAGCTTCTTGGGCTTC-3’'

Gene expression was determined by quantitative real-time PCR (LightCycler 480, Roche Diagnostics) using the SYBR ${ }^{\mathrm{R}}$ Premix Ex $\mathrm{Taq}^{\mathrm{TM}}$ (TaKaRa) according to the manufacturer's instructions with $1 \mu \mathrm{l}$ of cDNA in a total volume of $10 \mu \mathrm{l}$. The conditions of amplifications were performed as described previously by Wirth et al. (2007), except the first 10 minutes at $95^{\circ} \mathrm{C}$ which has become 30 seconds at $95^{\circ} \mathrm{C}$. All the results presented were standardized using the housekeeping gene Clathrin (At4g24550). Gene-specific primer sequences were: NRT2.1 forward, 5'-AACAAGGGCTAACGTGGATG-3'; NRT2.1 reverse, 5'CTGCTTCTCCTGCTCATTCC-3'; NAR2.1 forward, 5'- GGCCATGAAGTTGCCTATG -3'; NAR2.1 reverse, 5'- TCTTGGCCTTCCTCTTCTCA -3'; Clathrin forward, 5'AGCATACACTGCGTGCAAAG-3'; Clathrin reverse, 5'-TCGCCTGTGTCACATATCTC3 .

\section{$\mathrm{NO}_{3}^{-}$influx studies}

Root $\mathrm{NO}_{3}{ }^{-}$influx was assayed as described by (Delhon et al., 1995). Briefly, the plants were sequentially transferred to $0.1 \mathrm{mM} \mathrm{CaSO}_{4}$ for $1 \mathrm{~min}$, to a complete nutrient solution, $\mathrm{pH} 5.8$, containing $0.2 \mathrm{mM}^{15} \mathrm{NO}_{3}$ (99 atom $\%$ excess ${ }^{15} \mathrm{~N}$ ) for $5 \mathrm{~min}$, and finally to $0.1 \mathrm{mM} \mathrm{CaSO}_{4}$ for $1 \mathrm{~min}$. Roots were then separated from shoots, and the organs dried at $70{ }^{\circ} \mathrm{C}$ for $48 \mathrm{~h}$. After determination of their dry weight, the samples were analyzed for total nitrogen and atom $\%{ }^{15} \mathrm{~N}$ using a continuous flow isotope ratio mass spectrometer coupled with a $\mathrm{C} / \mathrm{N}$ elemental analyzer (model Euroflash Eurovector, Pavia Italy) as described in (Clarkson, 1986).

\section{NRT2.1 Immunodetection and Membrane purification}

Microsomes were prepared as described by (Giannini et al., 1987) and plasma membrane vesicles were purified from microsomes by aqueous two-phase partitioning, as described by (Santoni et al., 2003).

Proteins were separated on denaturing SDS-PAGE followed by an electrotransfer at $4{ }^{\circ} \mathrm{C}$ onto a PVDF membrane $(0.2 \mu \mathrm{M}$, Bio-Rad). NRT2.1 was detected using three different antiNRT2.1 antisera produced by Eurogentec against either the synthetic peptide TLEKAGEVAKDKFGK (anti-NRT2.1 19), CKNMHQGSLRFAENAK (anti-NRT2.1 20) or 
KNMHQG(p)SLRFAENAK (anti-S501P). NAR2.1 was detected using one anti-NAR2.1 antisera produced by Eurogentec against the synthetic peptide DVTTKPSREGPGVVL (antiNAR2.1). All the polyclonal antisera were affinity purified by Eurogentec. The immunodetection was performed with a chemiluminescent detection system kit (Pierce ${ }^{\mathrm{TM}} \mathrm{ECL}$ Western Blotting Substrate, Pierce).

For ELISA, serial 2-fold dilutions in a carbonate buffer $\left(30 \mathrm{mM} \mathrm{Na}_{2} \mathrm{CO}_{3}, 60 \mathrm{mM} \mathrm{NaHCO}\right.$, $\mathrm{pH}$ 9.5) of $20 \mu \mathrm{g}$ of microsomes proteins were loaded in duplicate on Maxisorb immunoplates (Nunc, Denmark) and left overnight at $4^{\circ} \mathrm{C}$. The immunodetection was performed according to the manufacturer's instructions. The primary anti-NRT2.1 20 (1:2500 dilution) and anti-S501P antibodies (1:500 dilution) and a secondary peroxidase-coupled anti-rabbit antibody were successively applied for $2 \mathrm{~h}$ at $37^{\circ} \mathrm{C}$. A linear regression between the absorbance signal due to oxidized 2,2'-azinobis-3-ethylbenzothiazolinz-6-sulfonic acid diammonium salt, as read with a multiplate reader (Victor, PerkinElmer Life sciences), ant the amount of proteins was obtained for each sample and used for relative comparison between samples.

For Dot blot analysis, the synthetic peptides, CKNMHQGSLRFAE and CKNMHQG(p)SLRFAE, produced by Eurogentec for the purification of the antibody antiS501P, were spotted onto a PVDF membrane (0.45 $\mu \mathrm{M}$, Hybond-P, Amersham). The membrane was then left to dry for $1.5 \mathrm{~h}$ at room temperature before being probed with S501-P antibody or the purified antibody produced against the non-modified peptide KNMHQGSLRFAENAK.

Blue Native PAGE (BN-PAGE) was adapted from (Peltier et al., 2001; Peltier et al., 2004) and (Kotur and Glass, 2015). A volume of plasma membrane (PM) resuspension buffer containing $10 \%$ dodecyl $\beta$-D-maltoside (DDM) was added to PM suspension to have $1.5 \%$ $\mathrm{DDM}$ in the final solution. After disruption of the samples with a potter and incubation at $4{ }^{\circ} \mathrm{C}$ for 15 min, solubilized samples were combined with 1/10 volume of sample loading buffer (5\% Serva Blue $\mathrm{G}$ in $50 \mathrm{mM}$ BisTris/ $\mathrm{HCl}$ (pH 7.2), $5 \mathrm{mM} \mathrm{MgCl}_{2}, 0.75 \mathrm{M}$ 6-amino-N-caproic acid, $20 \% \mathrm{w} / \mathrm{v}$ glycerol, $10 \% \mathrm{v} / \mathrm{v}$ protease inhibitors cocktail). After a second incubation at $4{ }^{\circ} \mathrm{C}$ for $15 \mathrm{~min}$, samples were applied to $1.5 \mathrm{~mm}$ thick $16 \times 16 \mathrm{~cm}$ native gradient gels $(5-16 \%$ acrylamide) in vertical electrophoresis unit operated at $4^{\circ} \mathrm{C}$. Gel lanes were then cut and the proteins were denaturated, reduced, and alkylated in SDS loading buffer ( $50 \mathrm{mM}$ Tris $\mathrm{pH} 6.8$, Urea $6 \mathrm{M}$, glycerol 30\% and SDS 2\%) containing either $100 \mathrm{mM}$ DTT for the first $30 \mathrm{~min}$ and $260 \mathrm{mM}$ iodoacetamid for another $30 \mathrm{~min}$. For separation in the second dimension, the gel lanes were then placed into a $12 \%$ acrylamide Tricine $16 \times 24 \mathrm{~cm}$ gel of the same thickness in vertical 
electrophoresis unit operated at room temperature and then transferred on a PVDF membrane $(0.2 \mu \mathrm{M}$, Bio-Rad) for immunodetection.

\section{Mass Spectrometry}

Microsomes of both wild-type Col-0 ecotype and GFP10 transgenic plants (Wirth et al., 2007) grown in hydroponics were used to determine NRT2.1 phosphorylation sites.

For S11, S28 and S501, the filter-aided sample preparation protocol (Wisniewski et al., 2009) was used to perform in solution reductions/alkylations simultaneously with detergent removing. The proteins were then subsequently digested at $37^{\circ} \mathrm{C}$ with Lys-C (Roche Applied Science) during $4 \mathrm{~h}$ then with trypsin (Sequencing Grade Modified, Promega, Madison, WI) overnight. Peptides were eluted by step elutions with $50 \mathrm{mM}$ ammonium bicarbonate, followed by a $50 \% \mathrm{ACN}$ and then $0.5 \mathrm{M} \mathrm{NaCl}$ elution steps. Peptides were desalted on $\mathrm{C} 18$ columns (Sep-Pak VactC18 cartridge 1cc, Waters). For Mass Spectrometry peptides were then concentrated with a precolumn (ThermoScientific, C18 PepMap100, $300 \mu \mathrm{m} \times 5 \mathrm{~mm}, 5 \mu \mathrm{m}$, $100 \AA$ ) and separated with a reversed-phase capillary column (ThermoScientific, C18 PepMap100, $75 \mu \mathrm{m} \times 250 \mathrm{~mm}, 3 \mu \mathrm{m}, 100 \AA$ ) over a $90 \mathrm{~min}$ gradient (300nL/min). Peptide fragmentation was carried out with a ion trap tandem MS system (AmaZon Speed ETD, Bruker) with nanoSprayer (Bruker), performed in the positive ion mode and alternating collision induced dissociation (CID) and electron transfer dissociation (ETD). MS and MS/MS spectra were acquired with a mass range of $\mathrm{m} / \mathrm{z}$ 300-1500 in enhanced resolution (FWHM 0,3u). ICC target was fixed to $4 \times 10^{4}$ ions with a maximum ion accumulation time set to $200 \mathrm{~ms}$. The corresponding data was processed via DataAnalysis 4.4 (Bruker). Data was interrogated via ProteinScape 4.0 (Bruker) against SwissProt restricted to Arabidopsis thaliana (thale cress) taxonomy using an in-house Mascot search server (Matrix Science; version 2.6). The selected enzyme was trypsin. Parameters of interrogation accepted one putative missed cleavage, a 0,8 $\mathrm{Da}$ and $2 \mathrm{Da}$ mass range for the parent peptide and for MS/MS fragment, respectively. Since proteins were reduced and alkylated, carbamidomethylation was selected as a fixed modification. Variable modifications were phosphorylation of serines, threonines, and tyrosines; oxidation of methionine; and acetylation of N-term proteins. For each analysis, peptides were determined by significant threshold $\mathrm{p}<0.05$.

For T521, immuno-purification was performed with $\mu$ MACS GFP Tag Protein Isolation kits (Miltenyi Biotec). $1 \mathrm{mg}$ of solubilized microsomes were loaded on $\mu$ columns. Kit protocol was followed. Proteins were eluted with elution buffer contained $50 \mathrm{mM}$ Tris $\mathrm{HCl}(\mathrm{pH} 6.8), 50 \mathrm{mM}$ 
DTT, 1\% SDS, $1 \mathrm{mM}$ EDTA, 0.005\% bromophenol blue, 10\% glycerol and conserved at $20^{\circ} \mathrm{C}$. The samples were then treated as described above except for peptide fragmentation which was carried out with a orbitrap MS system (LTQ-Orbitrap XL-ETD, ThermoScientific) with nanoSource (ThermoScientific), performed in the positive ion mode and alternating CID / ETD fragmentation. The corresponding data was processed via Xcalibur 2.0.7 (ThermoScientific) with the 3 most intense precursors, bi-charged with alternating CID/ETD fragmentation. Data was interrogated against a local NRT2.1-GFP database using an in-house Mascot search server (Matrix Science; version 2.4) with the same parameters as for S11, S28 and S501.

\section{rBiFC}

Open reading frames of NRT2.1 and NAR2.1 were amplified with gene-specific primers that included Gateway attachment sites (attB3/B2 or attB1/B4). Subsequent BP reactions in pDONR221-P3P2, and pDONR221-P1P4 (Invitrogen) yielded Entry clones that were verified via sequencing. NRT2.1 and NAR2.1 sequences were obtained without stop codon to allow Cterminal fusions. Gateway Destination clones were generated using LR Clonase II (Invitrogen) by LR reaction according to the manufacturer's instructions.

Point mutants were generated by site-directed mutagenesis kit (Agilent Technologies). Primers of different point mutants were designed by online tool QuikChange Primer Design (Agilent Technologies). All primers used for this experiment are listed in Table 1.

Agrobacterium tumefaciens strain GV3101 was used to transiently transform Nicotiana benthamiana with constructs as described previously through syringe mediated infiltration (Schob et al., 1997; Sparkes et al., 2006). Overnight cultures of agrobacteria were used to inoculate fresh LB medium (supplemented with $50 \mu \mathrm{g} / \mathrm{mL}$ rifampicin, and $100 \mu \mathrm{g} / \mathrm{mL}$ spectinomycin) and grown for another 4 to $6 \mathrm{~h}$ up to an optical density at $600 \mathrm{~nm}$ of 0.6 to 0.7 . Agrobacteria were harvested, and resuspended in AS medium (10 mM MgCl2, $10 \mathrm{mM}$ MES$\mathrm{KOH}, \mathrm{pH}$ 5.6, plus $150 \mathrm{mM}$ acetosyringone (Grefen et al., 2008; Blatt and Grefen, 2014)). After an incubation time of $60 \mathrm{~min}$ at room temperature, leaves of 4-week-old Nicotiana benthamiana were infiltrated as described previously (Schob et al., 1997; Sparkes et al., 2006; Blatt and Grefen, 2014). Leaves were subjected to CLSM analysis $2 \mathrm{~d}$ after infiltration.

For rBiFC assays, confocal images were collected using a Zeiss LSM700 confocal microscope with 20X/0.75-NA objectives. Excitation intensities, filter settings, and photomultiplier gains were standardized. YFP at excitation 514-nm and emission 521- to 565$\mathrm{nm}$, RFP at excitation 545-nm and emission 560- to 615-nm. 
rBiFC fluorescence ratios were calculated as a ratio of YFP and RFP fluorescence described previously (Grefen and Blatt, 2012).

\section{Acknowledgements}

The work was supported by an international grant from the ANR in France and DFG in Germany (SIPHON ANR-13-ISV6-0002-01), by a national grant from the ANR (TransN ANRBLAN-NT09_477214) and by post-doctoral funding from the CNRS (E.L.).

\section{Author contributions}

$\mathrm{AJ}$ performed most of the experiments including the generation and the characterisation of the transgenic plants, Western Blots and BN-PAGE. VC and LL obtained and performed experiments with the antibody anti-S501P and participated to BN-PAGE experiments. VC, FB and AnM performed root architecture experiments. AdM performed mass spectrometry experiments to find NRT2.1 phosphorylation sites along with VS and SH. AdM and EL optimised BN-PAGE protocol for NRT2.1. ZL and WS performed rBiFC experiments. PT performed ${ }^{15} \mathrm{~N}$ measurements, CF performed NRT2.1 sequence analysis and PB participated to the characterisation of the transgenic plants. LL and WS conceived the project and designed the experiments. LL, AG and WS interpreted the data and wrote the manuscript.

\section{References}

Blatt, M.R., and Grefen, C. (2014). Applications of fluorescent marker proteins in plant cell biology. Methods Mol Biol 1062: 487-507.

Bouguyon, E., Brun, F., Meynard, D., Kubeš, M., Pervent, M., Leran, S., Lacombe, B., Krouk, G., Guiderdoni, E., Zažímalová, E., Hoyerová, K., Nacry, P., and Gojon, A. (2015). Multiple mechanisms of nitrate sensing by Arabidopsis nitrate transceptor NRT1.1. Nature Plants 1: 15015.

Cerezo, M., Tillard, P., Filleur, S., Munos, S., Daniel-Vedele, F., and Gojon, A. (2001). Major alterations of the regulation of root $\mathrm{NO}(3)(-)$ uptake are associated with the mutation of Nrt2.1 and Nrt2.2 genes in Arabidopsis. Plant Physiol. 127: 262-271.

Clarkson, D.T. (1986). Regulation of absorption and release of nitrate by plant cells: a review of current ideas and methodology. In Developments in Plants and Soil Sciences: Fundamental, Ecological and Agricultural Aspect of Nitrogen Metabolism in Higher Plants (eds H. Lambers, J.J. Neeteson \& I.Stulen), Marttinus Nijhoff Publishers, Dordrecht, The Netherlands: 3-27. 
Clough, S.J., and Bent, A.F. (1998). Floral dip: a simplified method for agrobacteriummediated transformation of Arabidopsis thaliana. Plant J. 16(6): 735-743.

Delhon, P., Gojon, A., Tillard, P., and Passama, L. (1995). Diurnal regulation of $\mathrm{NO}_{3}{ }^{-}$uptake in soybean plants. I. Changes in $\mathrm{NO}_{3}^{-}$influx, efflux, and $\mathrm{N}$ utilization in the plant during the day/night cycle. J. Exp. Bot. 46: 1585-1594.

Edgar, R.C. (2004). MUSCLE: multiple sequence alignment with high accuracy and high throughput. Nucleic Acids Res. 32: 1792-1797.

Engelsberger, W.R., and Schulze, W.X. (2012). Nitrate and ammonium lead to distinct global dynamic phosphorylation patterns when resupplied to nitrogen-starved Arabidopsis seedlings. Plant J. 69: 978-995.

Filleur, S., Dorbe, M.F., Cerezo, M., Orsel, M., Granier, F., Gojon, A., and Daniel-Vedele, F. (2001). An arabidopsis T-DNA mutant affected in Nrt2 genes is impaired in nitrate uptake. FEBS Lett. 489: 220-224.

Forde, B.G. (2000). Nitrate transporters in plants: structure, function and regulation. Biochimica et Biophysica Acta 1465: 219-235.

Gansel, X., Munos, S., Tillard, P., and Gojon, A. (2001). Differential regulation of the NO3and $\mathrm{NH} 4+$ transporter genes AtNrt2.1 and AtAmt1.1 in Arabidopsis: relation with longdistance and local controls by N status of the plant. Plant J. 26: 143-155.

Giannini, J.L., Gildensoph, L.H., Reynolds-Niesman, I., and Briskin, D.P. (1987). Calcium Transport in Sealed Vesicles from Red Beet (Beta vulgaris L.) Storage Tissue : I. Characterization of a Ca-Pumping ATPase Associated with the Endoplasmic Reticulum. Plant Physiol. 85: 1129-1136.

Girin, T., Lejay, L., Wirth, J., Widiez, T., Palenchar, P.M., Nazoa, P., Touraine, B., Gojon, A., and Lepetit, M. (2007). Identification of a 150 bp cis-acting element of the AtNRT2.1 promoter involved in the regulation of gene expression by the $\mathrm{N}$ and $\mathrm{C}$ status of the plant. Plant Cell Environ 30: 1366-1380.

Gouy, M., Guindon, S., and Gascuel, O. (2010). SeaView version 4: A multiplatform graphical user interface for sequence alignment and phylogenetic tree building. Mol. Biol. Evol. 27: 221-224.

Grefen, C., and Blatt, M.R. (2012). A 2in1 cloning system enables ratiometric bimolecular fluorescence complementation (rBiFC). BioTechniques 53: 311-314.

Grefen, C., Stadele, K., Ruzicka, K., Obrdlik, P., Harter, K., and Horak, J. (2008). Subcellular localization and in vivo interactions of the Arabidopsis thaliana ethylene receptor family members. Mol Plant 1: 308-320.

Ho, C.H., Lin, S.H., Hu, H.C., and Tsay, Y.F. (2009). CHL1 functions as a nitrate sensor in plants. Cell 138: 1184-1194.

Huang, N.C., Liu, K.H., Lo, H.J., and Tsay, Y.F. (1999). Cloning and functional characterization of an Arabidopsis nitrate transporter gene that encodes a constitutive component of low-affinity uptake. The Plant Cell 11: 1381-1392. 
Ishikawa, S., Ito, Y., Sato, Y., Fukaya, Y., Takahashi, M., Morikawa, H., Ohtake, N., Ohyama, T., and Sueyoshi, K. (2009). Two-component high-affinity nitrate transport system in barley: membrane localization, protein expression in roots and a direct proteinprotein interaction. Plant Biotechnol. J. 26: 197-205.

Jacquot, A., Li, Z., Gojon, A., Schulze, W., and Lejay, L. (2017). Post-translational regulation of nitrogen transporters in plants and microorganisms. J. Exp. Bot. 68: 25672580 .

Kiba, T., Feria-Bourrellier, A.B., Lafouge, F., Lezhneva, L., Boutet-Mercey, S., Orsel, M., Brehaut, V., Miller, A., Daniel-Vedele, F., Sakakibara, H., and Krapp, A. (2012). The Arabidopsis nitrate transporter NRT2.4 plays a double role in roots and shoots of nitrogenstarved plants. Plant Cell 24: 245-258.

Kotur, Z., and Glass, A.D. (2015). A $150 \mathrm{kDa}$ plasma membrane complex of AtNRT2.5 and AtNAR2.1 is the major contributor to constitutive high-affinity nitrate influx in Arabidopsis thaliana. Plant Cell Environ. 38: 1490-1502.

Kotur, Z., Unkles, S.E., and Glass, A.D.M. (2017). Comparisons of the Arabidopsis thaliana High-affinity Nitrate Transporter Complex AtNRT2.1/AtNAR2.1 and the Aspergillus nidulans AnNRTA: structure function considerations

. Isr. J. Plant Sci. 64: 21-31.

Krapp, A., David, L.C., Chardin, C., Girin, T., Marmagne, A., Leprince, A.S., Chaillou, S., Ferrario-Mery, S., Meyer, C., and Daniel-Vedele, F. (2014). Nitrate transport and signalling in Arabidopsis. J. Exp. Bot. 65: 789-798.

Krouk, G., Tillard, P., and Gojon, A. (2006). Regulation of the high-affinity NO3- uptake system by NRT1.1-mediated NO3- demand signaling in Arabidopsis. Plant Physiol. 142: 1075-1086.

Krouk, G., Lacombe, B., Bielach, A., Perrine-Walker, F., Malinska, K., Mounier, E., Hoyerova, K., Tillard, P., Leon, S., Ljung, K., Zazimalova, E., Benkova, E., Nacry, P., and Gojon, A. (2010). Nitrate-regulated auxin transport by NRT1.1 defines a mechanism for nutrient sensing in plants. Dev. Cell 18: 927-937.

Lanquar, V., and Frommer, W.B. (2010). Adjusting ammonium uptake via phosphorylation. Plant Signal. Behav. 5: 736-738.

Lanquar, V., Loque, D., Hormann, F., Yuan, L., Bohner, A., Engelsberger, W.R., Lalonde, S., Schulze, W.X., von Wiren, N., and Frommer, W.B. (2009). Feedback inhibition of ammonium uptake by a phospho-dependent allosteric mechanism in Arabidopsis. Plant Cell 21: $3610-3622$.

Laugier, E., Bouguyon, E., Mauries, A., Tillard, P., Gojon, A., and Lejay, L. (2012). Regulation of high-affinity nitrate uptake in roots of Arabidopsis depends predominantly on posttranscriptional control of the NRT2.1/NAR2.1 transport system. Plant Physiol. 158: 1067-1078.

Lejay, L., Wirth, J., Pervent, M., Cross, J.M., Tillard, P., and Gojon, A. (2008). Oxidative pentose phosphate pathway-dependent sugar sensing as a mechanism for regulation of root ion transporters by photosynthesis. Plant Physiol. 146: 2036-2053. 
Lejay, L., Tillard, P., Lepetit, M., Olive, F., Filleur, S., Daniel-Vedele, F., and Gojon, A. (1999). Molecular and functional regulation of two NO3- uptake systems by N- and C-status of Arabidopsis plants. Plant J. 18: 509-519.

Lejay, L., Gansel, X., Cerezo, M., Tillard, P., Muller, C., Krapp, A., von Wiren, N., DanielVedele, F., and Gojon, A. (2003). Regulation of root ion transporters by photosynthesis: functional importance and relation with hexokinase. Plant Cell 15: 2218-2232.

Lezhneva, L., Kiba, T., Feria-Bourrellier, A.B., Lafouge, F., Boutet-Mercey, S., Zoufan, P., Sakakibara, H., Daniel-Vedele, F., and Krapp, A. (2014). The Arabidopsis nitrate transporter NRT2.5 plays a role in nitrate acquisition and remobilization in nitrogen-starved plants. Plant J. 80: 230-241.

Li, W., Wang, Y., Okamoto, M., Crawford, N.M., Siddiqi, M.Y., and Glass, A.D. (2007). Dissection of the AtNRT2.1:AtNRT2.2 inducible high-affinity nitrate transporter gene cluster. Plant Physiol. 143: 425-433.

Little, D.Y., Rao, H., Oliva, S., Daniel-Vedele, F., Krapp, A., and Malamy, J.E. (2005). The putative high-affinity nitrate transporter NRT2.1 represses lateral root initiation in response to nutritional cues. Proc. Natl. Acad. Sci. of the USA 102: 13693-13698.

Liu, K.H., and Tsay, Y.F. (2003). Switching between the two action modes of the dual-affinity nitrate transporter CHL1 by phosphorylation. EMBO J. 22: 1005-1013.

Loque, D., Lalonde, S., Looger, L.L., von Wiren, N., and Frommer, W.B. (2007). A cytosolic trans-activation domain essential for ammonium uptake. Nature 446: 195-198.

Lorenz, M.C., and Heitman, J. (1998). The MEP2 ammonium permease regulates pseudohyphal differentiation in Saccharomyces cerevisiae. EMBO J. 17: 1236-1247.

Malamy, J.E., and Ryan, K.S. (2001). Environmental regulation of lateral root initiation in Arabidopsis. Plant Physiol. 127: 899-909.

Menz, J., Li, Z., Schulze, W.X., and Ludewig, U. (2016). Early nitrogen-deprivation responses in Arabidopsis roots reveal distinct differences on transcriptome and (phospho-) proteome levels between nitrate and ammonium nutrition. Plant J. 88: 717-734.

Miller, A.J., Fan, X., Orsel, M., Smith, S.J., and Wells, D.M. (2007). Nitrate transport and signalling. J. Exp. Bot. 58: 2297-2306.

Munos, S., Cazettes, C., Fizames, C., Gaymard, F., Tillard, P., Lepetit, M., Lejay, L., and Gojon, A. (2004). Transcript profiling in the chl1-5 mutant of Arabidopsis reveals a role of the nitrate transporter NRT11 in the regulation of another nitrate transporter, NRT2.1. Plant Cell 16: 2433-2447.

Navarro, F.J., Martin, Y., and Siverio, J.M. (2008). Phosphorylation of the Yeast Nitrate Transporter Ynt1 Is Essential for Delivery to the Plasma Membrane during Nitrogen Limitation. J. Biol. Chem. 283: 31208-31217.

O'Brien, J.A., Vega, A., Bouguyon, E., Krouk, G., Gojon, A., Coruzzi, G., and Gutierrez, R.A. (2016). Nitrate Transport, Sensing, and Responses in Plants. Mol. Plant 9: 837-856. 
Okamoto, M., Kumar, A., Li, W., Wang, Y., Siddiqi, M.Y., Crawford, N.M., and Glass, A.D. (2006). High-affinity nitrate transport in roots of Arabidopsis depends on expression of the NAR2-like gene AtNRT3.1. Plant Physiol. 140: 1036-1046.

Omasits, U., Ahrens, C.H., Muller, S., and Wollscheid, B. (2014). Protter: interactive protein feature visualization and integration with experimental proteomic data. Bioinformatics 30: 884-886.

Orsel, M., Eulenburg, K., Krapp, A., and Daniel-Vedele, F. (2004). Disruption of the nitrate transporter genes AtNRT2.1 and AtNRT2.2 restricts growth at low external nitrate concentration. Planta 219: 714-721.

Orsel, M., Chopin, F., Leleu, O., Smith, S.J., Krapp, A., Daniel-Vedele, F., and Miller, A.J. (2006). Characterization of a two-component high-affinity nitrate uptake system in Arabidopsis. Physiology and protein-protein interaction. Plant Physiol. 142: 1304-1317.

Pawson, T., and Scott, J.D. (1997). Signaling through scaffold, anchoring, and adaptor proteins. Science 278: 2075-2080.

Peltier, J.B., Ytterberg, J., Liberles, D.A., Roepstorff, P., and van Wijk, K.J. (2001). Identification of a $350-\mathrm{kDa}$ ClpP protease complex with 10 different Clp isoforms in chloroplasts of Arabidopsis thaliana. J. Biol. Chem. 276: 16318-16327.

Peltier, J.B., Ripoll, D.R., Friso, G., Rudella, A., Cai, Y., Ytterberg, J., Giacomelli, L., Pillardy, J., and van Wijk, K.J. (2004). Clp protease complexes from photosynthetic and non-photosynthetic plastids and mitochondria of plants, their predicted three-dimensional structures, and functional implications. J. Biol. Chem. 279: 4768-4781.

Quesada, A., Galvan, A., and Fernandez, E. (1994). Identification of nitrate transporter genes in Chlamydomonas reinhardtii. Plant J. 5: 407-419.

Rawat, S., Erner, Y., Kronzucker, H., Silim, S., Schjoerring, J.K., Siddiqi, M.Y., and Glass, A. (1999). AtAMT1 transcript abundance and high affinity ammonium influx in roots of Arabidopsis. Plant J. 19: 143-152

Remans, T., Nacry, P., Pervent, M., Girin, T., Tillard, P., Lepetit, M., and Gojon, A. (2006). A central role for the nitrate transporter NRT2.1 in the integrated morphological and physiological responses of the root system to nitrogen limitation in Arabidopsis. Plant Physiol. 140: 909-921.

Santoni, V., Vinh, J., Pflieger, D., Sommerer, N., and Maurel, C. (2003). A proteomic study reveals novel insights into the diversity of aquaporin forms expressed in the plasma membrane of plant roots. Biochem. J. 373: 289-296.

Schob, H., Kunz, C., and Meins, F., Jr. (1997). Silencing of transgenes introduced into leaves by agroinfiltration: a simple, rapid method for investigating sequence requirements for gene silencing. Mol. Gen. Genet. 256: 581-585.

Sparkes, I.A., Runions, J., Kearns, A., and Hawes, C. (2006). Rapid, transient expression of fluorescent fusion proteins in tobacco plants and generation of stably transformed plants. Nat. Protoc. 1: 2019-2025. 
Tong, Y., Zhou, J.J., Li, Z., and Miller, A.J. (2005). A two-component high-affinity nitrate uptake system in barley. Plant J. 41: 442-450.

Tsay, Y.F., Schroeder, J.I., Feldmann, K.A., and Crawford, N.M. (1993). The herbicide sensitivity gene CHL1 of Arabidopsis encodes a nitrate-inducible nitrate transporter. Cell 72: 705-713.

Tsay, Y.F., Chiu, C.C., Tsai, C.B., Ho, C.H., and Hsu, P.K. (2007). Nitrate transporters and peptide transporters. FEBS Lett. 581: 2290-2300.

Van Nuland, A., Vandormael, P., Donaton, M., Alenquer, M., Lourenco, A., Quintino, E., Versele, M., and Thevelein, J.M. (2006). Ammonium permease-based sensing mechanism for rapid ammonium activation of the protein kinase A pathway in yeast. Mol. Microbiol. 59: $1485-1505$.

Wang, Y.Y., Cheng, Y.H., Chen, K.E., and Tsay, Y.F. (2018). Nitrate Transport, Signaling, and Use Efficiency. Annu. Rev. Plant Biol. 69: 85-122.

Wirth, J., Chopin, F., Santoni, V., Viennois, G., Tillard, P., Krapp, A., Lejay, L., DanielVedele, F., and Gojon, A. (2007). Regulation of root nitrate uptake at the NRT2.1 protein level in Arabidopsis thaliana. J. Biol. Chem. 282: 23541-23552.

Wisniewski, J.R., Zougman, A., Nagaraj, N., and Mann, M. (2009). Universal sample preparation method for proteome analysis. Nat. Methods 6: 359-362.

Yong, Z., Kotur, Z., and Glass, A.D. (2010). Characterization of an intact two-component high-affinity nitrate transporter from Arabidopsis roots. Plant J. 63: 739-748.

\section{Figure legends}

Figure 1. Membrane topology of NRT2.1 using Protter (Omasits et al., 2014), with the epitopes corresponding to NRT2.1 antibodies (19) and (20) and the localisation of NRT2.1 C-terminal parts removed in the plants called $\Delta \mathrm{C}_{494-530}$ (without epitope 20) and $\Delta \mathrm{C}_{514-530}$ (with epitope 20).

Figure 2. Characterization of Arabidopsis transgenic lines expressing truncated forms of NRT2.1 in the C-terminus of the protein.

Wild type (Col), nrt2.1-2 knockout mutant (nrt2.1) and transgenic lines expressing truncated forms of NRT2.1 without ( $\Delta 3 \mathrm{C}_{494-530}$ and $\left.\Delta 5 \mathrm{C}_{494-530}\right)$ or with epitope $20\left(\Delta 3 \mathrm{C}_{514-530}\right.$ and $\Delta 6 \mathrm{C}_{514-}$ 530 ). Plants were grown on $1 \mathrm{mM} \mathrm{NO}_{3}^{-}$for 5 weeks and were starved for $\mathrm{N}$ during 5 days. Thereafter, the plants were re-supplied with $1 \mathrm{mM} \mathrm{NO}^{3}$ during $4 \mathrm{~h}$ or $7 \mathrm{~h}$. 
(A) Phenotype of the plants grown on $1 \mathrm{mM} \mathrm{NO}_{3}^{-}$.

(B) Root $\mathrm{NO}_{3}^{-}$influx measured at the external concentration of $0.2 \mathrm{mM}^{15} \mathrm{NO}_{3}^{-}$(Values are means of 12 replicates $\pm \mathrm{SD})$.

(C) and (D) Root NRT2.1 and NAR2.1 expression quantified by QPCR (Values are means of three replicates $\pm \mathrm{SD})$.

Figure 3. NRT2.1 and NAR2.1 protein level and protein complex in the transgenic lines expressing truncated forms of NRT2.1 in the C-terminus of the protein.

(A) and (B) Immunoblot for NAR2.1 and NRT2.1 using plasma membranes extracted from roots of wild type $(\mathrm{Col})$ and transgenic lines expressing truncated forms of NRT2.1 with $\left(\Delta 3 \mathrm{C}_{514-530}\right)$ or without epitope $20\left(\Delta 5 \mathrm{C}_{494-530}\right)$. Plants were grown on $1 \mathrm{mM} \mathrm{NO}_{3}{ }^{-}$for 5 weeks and were starved for $\mathrm{N}$ during 5 days. Thereafter, the plants were re-supplied with $1 \mathrm{mM} \mathrm{NO}_{3}^{-}$ during 4h. (A) Immunoblot for NRT2.1 using anti-NRT2.1(19) antibody. (B) Immunoblot for NRT2.1 using anti-NRT2.1 (20) antibody. Samples were separated on a 12\% SDS-PAGE (10 $\mu \mathrm{g}$ of protein/lane).

(C), (D) and (E) Blue-native PAGE (BN-PAGE) for NRT2.1 and NAR2.1 complex, using microsomes extracted from roots of wild-type (Col) grown on $1 \mathrm{mM} \mathrm{NO}_{3}{ }^{-}(\mathbf{C})$ and $\Delta 3 \mathrm{C}_{514-530}$ (D) and $\Delta 5 \mathrm{C}_{494-530}$ (E) transgenic lines, after $4 \mathrm{~h}$ of $\mathrm{NO}_{3}$ - re-supply. Membranes were probed with both anti-NRT2.1 20 and anti-NAR2.1 antibodies.

Figure 4. Identification of NRT2.1 phosphorylation sites.

(A) S11 : MS/MS spectrum corresponding to a serie of $\mathrm{z}$ ions resulting from ETD fragmentation of NRT2.1 peptide (ion score Mascot 2.6: 67 ; site phosphorylation probability Mascot 2.6: $96.42 \%$ ). Data analysis led to the identification of the sequence GDSTGEPGSS*MHGVTGR with phosphorylation of S11. S28 and S501 : MS/MS spectrum corresponding to a series of c and $\mathrm{z}$ ions resulting from ETD fragmentation of NRT2.1 peptides: S28: ion score Mascot 2.6: 80 ; site phosphorylation probability Mascot 2.6: 99.66\%; S501: ion score Mascot 2.6: 54. Data analysis led to the identification of the sequence EQSFAFSVQS*PIVHTDK with phosphorylation of S28 and of the sequence NMHQGS*LRFAENAK with phosphorylation of S501. T521 : MS/MS spectrum and fragmentation table corresponding to a series of $\mathrm{b}$ and $\mathrm{y}$ ions that resulted from CID fragmentation of NRT2.1-GFP peptide (ion score Mascot 2.6: 50 ; 
site phosphorylation probability Mascot 2.6: 92.69\%). Data analysis led to identification of the sequence SAAT*PPENTPNNVK with phosphorylation of T521.

(B) Membrane topology of NRT2.1 using Protter (Omasits et al., 2014), with the epitope corresponding to NRT2.1 antibody (20) and the localisation of the phosphorylation sites identified by mass spectrometry.

Figure 5. Characterization of Arabidopsis transgenic lines expressing mutated forms of NRT2.1 on the phosphorylation site S501.

Wild type (Col), nrt2.1-2 knockout mutant (nrt2.1) and transgenic lines expressing mutated forms of NRT2.1, which either cannot be phosphorylated (S501A7 and S501A9) or mimic a constitutive phosphorylation of S501 (S501D1 and S501D2). Plants were grown on $1 \mathrm{mM} \mathrm{NO}_{3}^{-}$ for 5 weeks and were starved for $\mathrm{N}$ during 5 days. Thereafter, the plants were re-supplied with $1 \mathrm{mM} \mathrm{NO}_{3}{ }^{-}$during $4 \mathrm{~h}$ and $7 \mathrm{~h}$.

(A) Phenotype of the plants grown on $1 \mathrm{mM} \mathrm{NO}_{3}^{-}$.

(B) Root $\mathrm{NO}_{3}{ }^{-}$influx measured at the external concentration of $0.2 \mathrm{mM}^{15} \mathrm{NO}_{3}^{-}$(Values are means of 12 replicates $\pm \mathrm{SD})$.

(C) and (D) Root NRT2.1 and NAR2.1 expression quantified by QPCR (Values are means of three replicates $\pm \mathrm{SD}$ ).

Figure 6. NRT2.1 and NAR2.1 protein level and protein complex in the transgenic lines expressing mutated forms of NRT2.1 for S501 phosphorylation site.

(A) and (B) Immunoblot for NAR2.1 and NRT2.1 using plasma membranes extracted from roots of wild type $(\mathrm{Col})$ and transgenic lines expressing mutated forms of NRT2.1, which either cannot be phosphorylated (S501A9) or mimic a constitutive phosphorylation on S501 (S501D2). Plants were grown on $1 \mathrm{mM} \mathrm{NO}_{3}{ }^{-}$for 5 weeks and were starved for $\mathrm{N}$ during 5 days. Thereafter, the plants were re-supplied with $1 \mathrm{mM} \mathrm{NO}_{3}{ }^{-}$during $4 \mathrm{~h}$. (A) Immunoblot for NRT2.1 using anti-NRT2.1(19) antibody. (B) Immunoblot for NRT2.1 using anti-NRT2.1 (20) antibody. Samples were separated on a $12 \%$ SDS-PAGE (10 $\mu \mathrm{g}$ of protein/lane).

(C) and (D) Blue-native PAGE (BN-PAGE) for NRT2.1 and NAR2.1 complex, using microsomes extracted from roots of S501A9 (C) and S501D2 (D) transgenic lines, after 4h of $\mathrm{NO}_{3}$ - re-supply. Membranes were probed with both anti-NRT2.1 (20) and anti-NAR2.1 antibodies. 
(E) $\mathrm{rBiFC}$ fluorescence signals from five independent experiments using tobacco plants transformed with the pBiFCt-2in1-CC vector. Each box plot represents the mean of fluorescence intensity ratios from more than 12 images taken at random over the leaf surface. rBiFC signals were calculated as the mean fluorescence intensity ratio of YFP to RFP determined from each image set.

Figure 7. Regulation of NRT2.1 S501 phosphorylation in response to $\mathrm{NO}_{3}{ }^{-}$.

Wild type plants were grown on $1 \mathrm{mM} \mathrm{NO}_{3}^{-}$for 5 weeks and were starved for $\mathrm{N}$ during 5 days. Thereafter, the plants were re-supplied with $1 \mathrm{mM} \mathrm{NO}_{3}^{-}$during $1 \mathrm{~h}$ or $4 \mathrm{~h}$. Knock-out plants for NRT2.1 (KO) were grown on $1 \mathrm{mM} \mathrm{NO}^{-}$

(A) Immunoblot for NRT2.1 S501 phosphorylation site (Anti-S501-P) and NRT2.1 (AntiNRT2.1-20) using microsomes extracted from roots. Samples were separated on a $12 \%$ SDSPAGE (20 $\mu \mathrm{g}$ of protein/lane).

(B) ELISA from three independent experiments for NRT2.1 phosphorylation site (S501-P) and NRT2.1 using microsomes extracted from roots.

Figure 8. Impact of S501A and S501D mutations on lateral root density in response to $\mathrm{NO}_{3}{ }^{-}$

Density of initiated primordia corresponding to the total number of primordia plus lateral roots normalized by the length of the primary root of wild type (Col), nrt2.1-2 knockout mutant (nrt2.1) and S501A9 or S501D2 transgenic lines. Plants were transferred at day 5 from $1 \mathrm{mM}$ $\mathrm{NO}_{3}{ }^{-}$to either nitrogen-free medium $(0 \mathrm{~N})$ or 0,3 and $5 \mathrm{mM} \mathrm{NO}_{3}{ }^{-}$. Total number of visible LRs and LR primordia were determined between day 10 and 12. Average values are means of at least 20 replicates $\pm \mathrm{SD} . * \mathrm{P}<0.05, * * \mathrm{P}<0.01$ and $* * * \mathrm{P}<0,001$ calculated by unpaired Sudents t-test compared to $n r t 2.1$.

Figure 9. Model for the regulation of NRT2.1 activity

NRT2.1 is represented with NAR2.1 interacting with its N-terminus and the red stars indicate S501 phosphorylation in NRT2.1 C-terminus part. The blue and pink disks represent hypothetical partner proteins, which could respectively participate in the inactivation and the activation of NRT2.1 protein complex. Under non inductive conditions, S501 is phosphorylated, the pores of NRT2.1 are closed and the protein complex is inactive. On 
inductive conditions, the protein complex with the phosphorylated form of NRT2.1 is dissociated and replaced by a protein complex containing new forms of non-phosphorylated NRT2.1. The absence of NRT2.1 S501 phosphorylation in the protein complex open the pores and enable $\mathrm{NO}_{3}{ }^{-}$to enter the root.

Figure 10. NRT2.1 C-terminus part alignment performed using Muscle v3.8.31 (Edgar, 2004) and displayed with SeaView version 4 (Gouy et al., 2010).

Supplemental Figure 1. Root $\mathrm{NO}_{3}{ }^{-}$influx in response to sucrose, light and $\mathrm{NH}_{4} \mathrm{NO}_{3}$ in the transgenic lines $\Delta \mathrm{C}_{494-530}, \Delta \mathrm{C}_{514-530}, \mathrm{~S} 501 \mathrm{~A}$ and $\mathrm{S} 501 \mathrm{D}$.

(A) Plants were grown on $1 \mathrm{mM} \mathrm{NO}^{-}$and after a normal night were either kept in the dark during $4 \mathrm{~h}$ on a complete nutrient solution with or without $1 \%$ sucrose or transferred during $4 \mathrm{~h}$ in the light.

(B) Plants were grown on $1 \mathrm{mM} \mathrm{NO}_{3}{ }^{-}$and were transferred during $4 \mathrm{~h}$ on a solution containing $10 \mathrm{mM} \mathrm{NH}_{4} \mathrm{NO}_{3}$.

Root $\mathrm{NO}_{3}{ }^{-}$influx was measured at the external concentration of $0.2 \mathrm{mM}^{15} \mathrm{NO}_{3}{ }^{-}$. Values are means of 12 replicates $\pm \mathrm{SD}$.

Supplemental Figure 2. rBiFC analysis for NRT2.1 and NAR2.1 interaction.

rBiFC analysis of YFP and RFP fluorescence collected from tobacco plants transformed using the pBiFCt-2in1-CC vector. Left to right, images are YFP (BiFC) fluorescence, RFP fluoresence and bright field. Bar $=50 \mu \mathrm{m}$

Supplemental Figure 3. Dot blot analysis for the specificity of the antibody Anti-S501P.

Serial 2 fold dilution of $3 \mu \mathrm{g}$ of synthetic peptides phosphorylated or not on S501 were blotted. Membranes were probed with either the antibody specific for S501 phosphorylation (AntiS501P) or the antibody non-specific to the modification.

Supplemental Figure 4. Root $\mathrm{NO}_{3}^{-}$influx after $1 \mathrm{~h}$ and $4 \mathrm{~h}$ of $\mathrm{NO}_{3}^{-}$induction. 
bioRxiv preprint first posted online Mar. 20, 2019; doi: http://dx.doi.org/10.1101/583542. The copyright holder for this preprint (which was not peer-reviewed) is the author/funder, who has granted bioRxiv a license to display the preprint in perpetuity. All rights reserved. No reuse allowed without permission.

Wild type (Col) and nrt2.1-2 knockout mutant (nrt2.1) were grown on $1 \mathrm{mM} \mathrm{NO}_{3}^{-}$for 5 weeks and were starved for $\mathrm{N}$ during 5 days. Thereafter, the plants were re-supplied with $1 \mathrm{mM} \mathrm{NO}_{3}^{-}$ during $1 \mathrm{~h}$ or $4 \mathrm{~h}$. Root $\mathrm{NO}_{3}{ }^{-}$influx was measured at the external concentration of $0.2 \mathrm{mM}^{15} \mathrm{NO}_{3}$. Values are means of 12 replicates $\pm \mathrm{SD}$.

Table 1: Oligonucleotides used for Entry clone design and site-directed mutagenesis (SDM)

\begin{tabular}{|c|c|}
\hline Name & Sequence (5'-3') \\
\hline attB3-NAR2.1 & ggggacaactttgtataataaagttgtaATGGCGATCCAGAAGATC \\
\hline attB2-NAR2.1 & ggggaccactttgtacaagaaagctgggttTTTGCTTTGCTCTATCTT \\
\hline attB1-NRT2.1 & ggggacaagtttgtacaaaaaagcaggcttaATGGGTGATTCTACTGGT \\
\hline attB4-NRT2.1 & ggggacaactttgtatagaaaagttgggtgAACATTGTTGGGTGTGT \\
\hline $\begin{array}{l}\text { SDM-S- } \\
\text { NRT2.1 }{ }^{\mathrm{S} 501 \mathrm{~A}}\end{array}$ & ATCAAGGAGCCCTCCGGTTT \\
\hline $\begin{array}{l}\text { SDM-A- } \\
\text { NRT2.1 }\end{array}$ & AAACCGGAGGGCTCCTTGAT \\
\hline $\begin{array}{l}\text { SDM-S- } \\
\text { NRT2.1 }\end{array}$ & ATCAAGGAGACCTCCGGTTT \\
\hline $\begin{array}{l}\text { SDM-A- } \\
\text { NRT2.1 }\end{array}$ & AAACCGGAGGTCTCCTTGAT \\
\hline
\end{tabular}




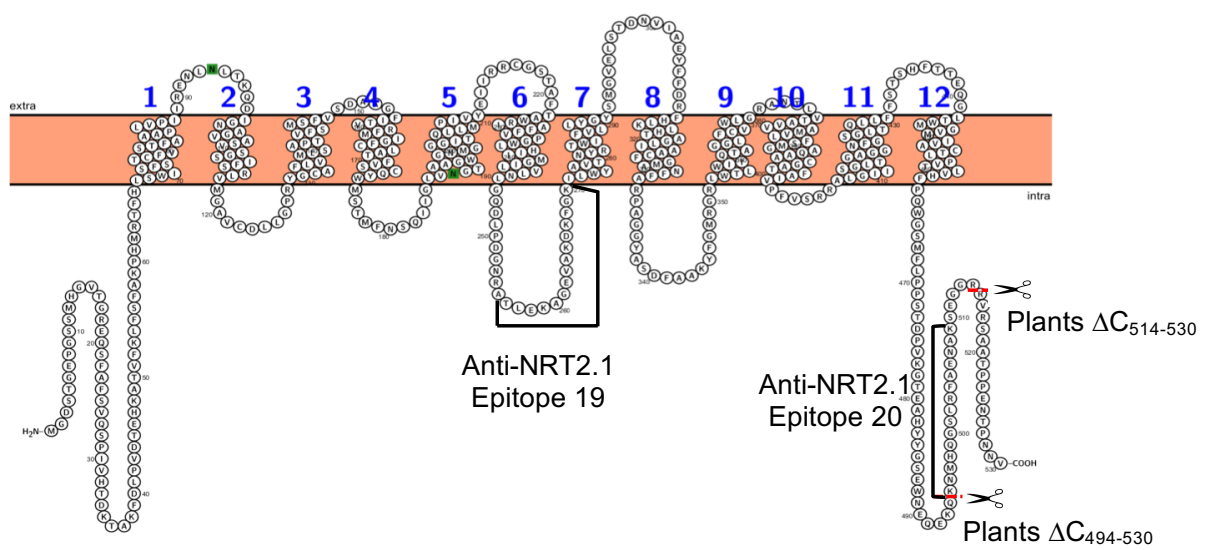

Figure 1. Membrane topology of NRT2.1 using Protter (Omasits et al., 2014), with the epitopes corresponding to NRT2.1 antibodies (19) and (20) and the localisation of NRT2.1 C-terminal parts removed in the plants called $\Delta \mathrm{C}_{494-530}$ (without epitope 20) and $\Delta \mathrm{C}_{514-530}$ (with epitope 20). 
A

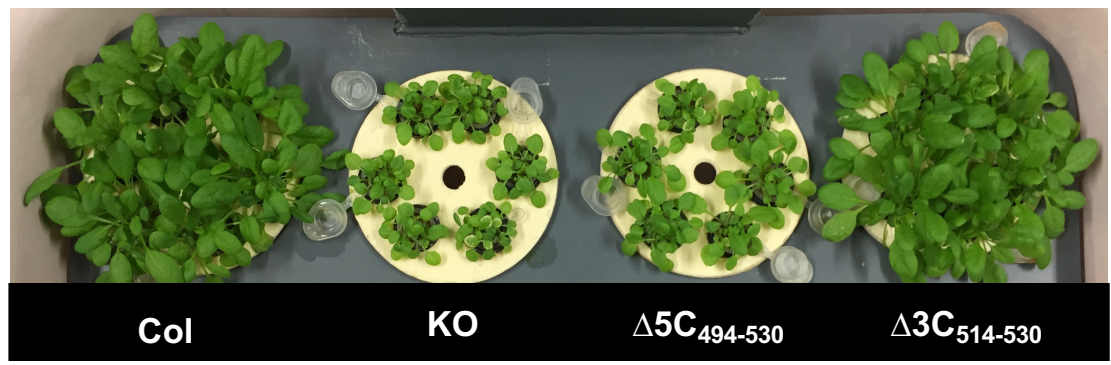

B

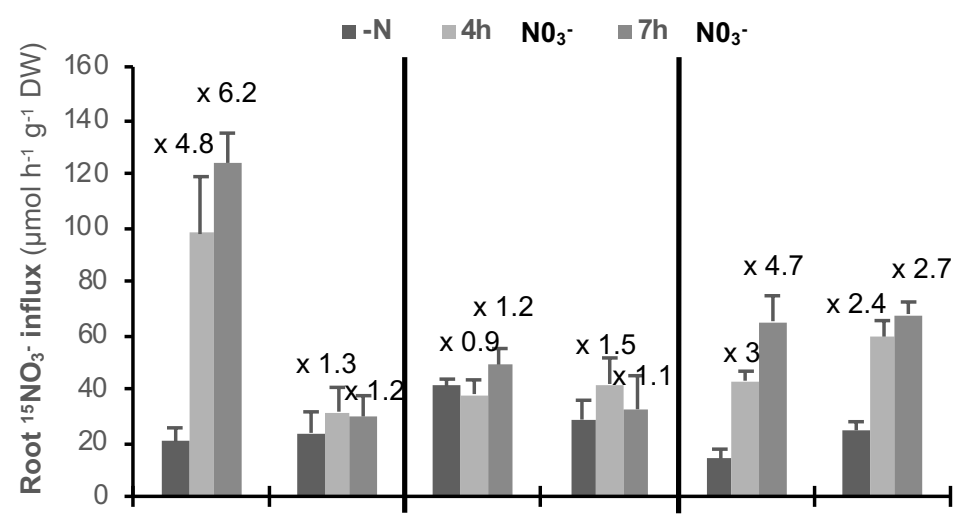

C

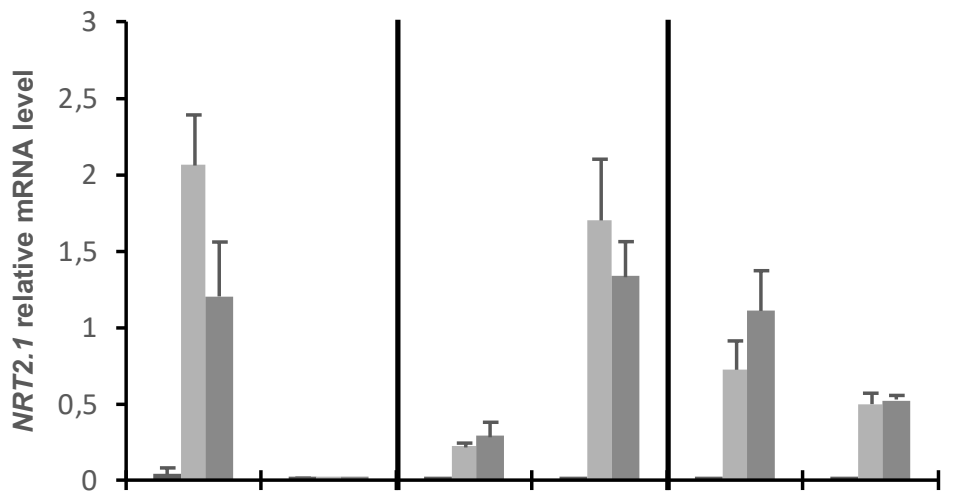

D

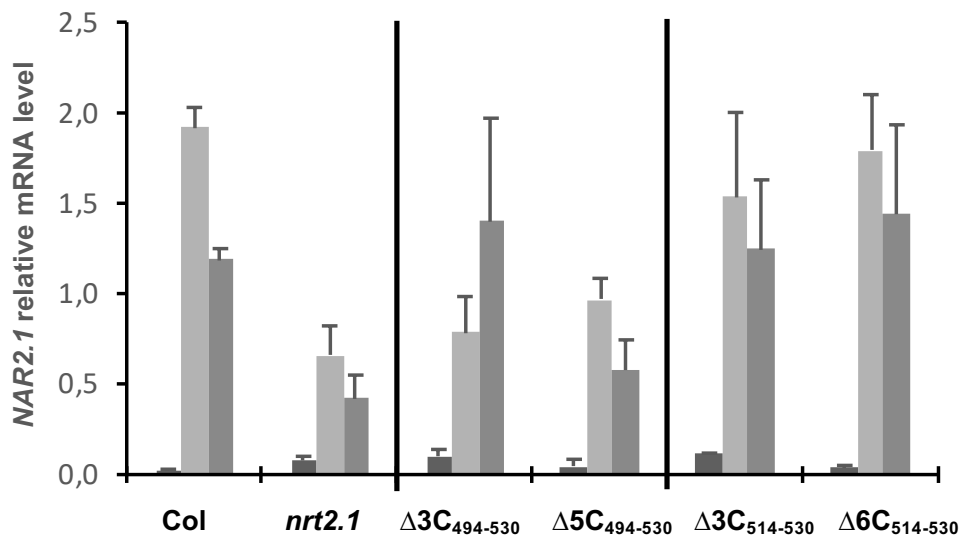

Figure 2. Characterization of Arabidopsis transgenic lines expressing truncated forms of NRT2.1 in the Cterminus of the protein.

Wild type (Col), nrt2.1-2 knockout mutant (nrt2.1) and transgenic lines expressing truncated forms of NRT2.1 without $\left(\Delta 3 \mathrm{C}_{494-530}\right.$ and $\left.\Delta 5 \mathrm{C}_{494-530}\right)$ or with epitope $20\left(\Delta 3 \mathrm{C}_{514-530}\right.$ and $\left.\Delta 6 \mathrm{C}_{514-530}\right)$. Plants were grown on $1 \mathrm{mM}$ $\mathrm{NO}_{3}{ }^{-}$for 5 weeks and were starved for $\mathrm{N}$ during 5 days. Thereafter, the plants were re-supplied with $1 \mathrm{mM}$ $\mathrm{NO}_{3}^{-}$during $4 \mathrm{~h}$ or $7 \mathrm{~h}$.

(A) Phenotype of the plants grown on $1 \mathrm{mM} \mathrm{NO}_{3}^{-}$.

(B) Root $\mathrm{NO}_{3}{ }^{-}$influx measured at the external concentration of $0.2 \mathrm{mM}^{15} \mathrm{NO}_{3}{ }^{-}$(Values are means of 12 replicates \pm SD).

(C) and (D) Root NRT2.1 and NAR2.1 expression quantified by QPCR (Values are means of three replicates \pm $\mathrm{SD})$. 

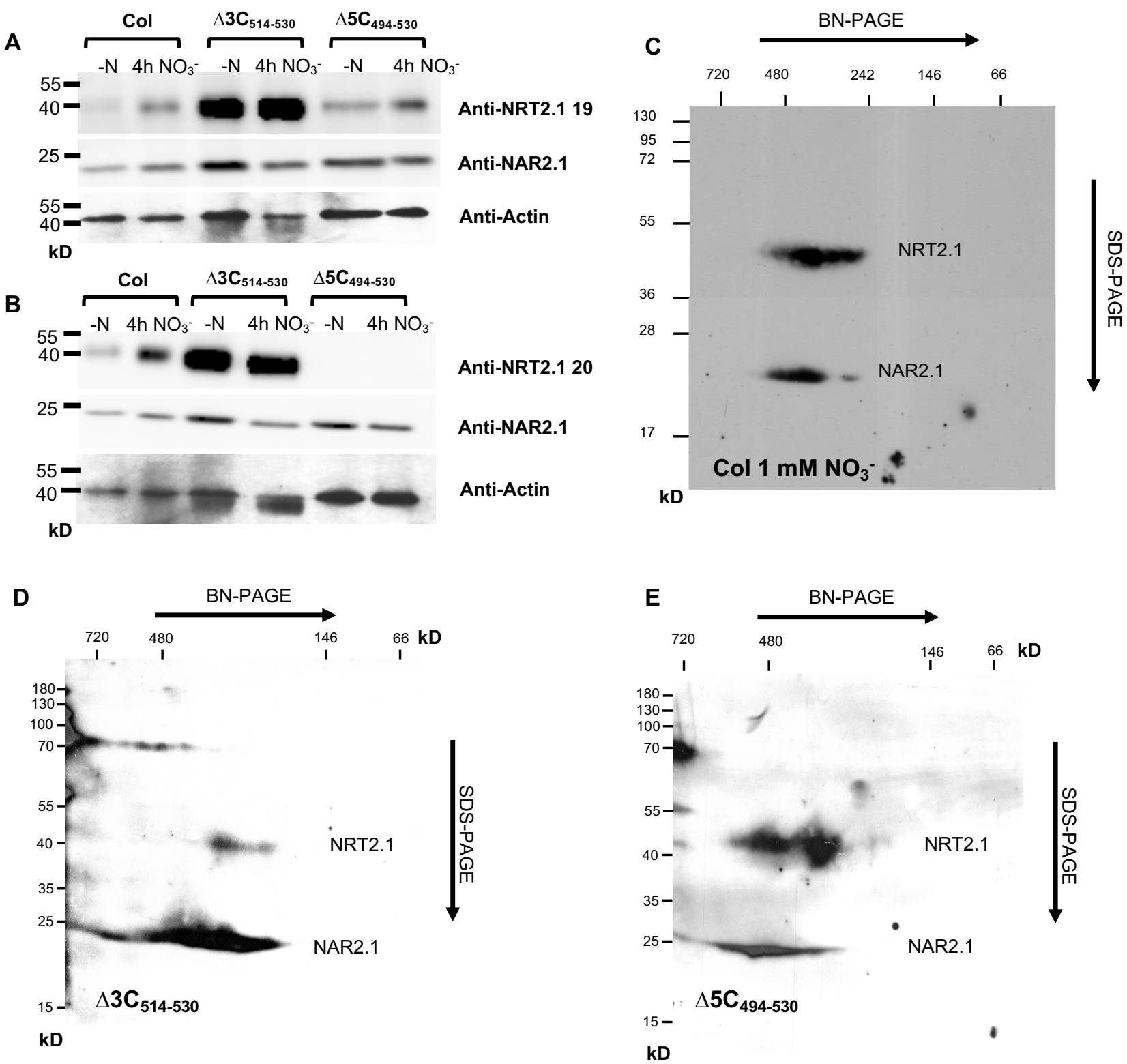

Figure 3. NRT2.1 and NAR2.1 protein level and protein complex in the transgenic lines expressing truncated forms of NRT2.1 in the C-terminus of the protein.

(A) and (B) Immunoblot for NAR2.1 and NRT2.1 using plasma membranes extracted from roots of wild type (Col) and transgenic lines expressing truncated forms of NRT2.1 with $\left(\Delta 3 \mathrm{C}_{514-530}\right)$ or without epitope 20 $\left(\Delta 5 \mathrm{C}_{494-530}\right)$. Plants were grown on $1 \mathrm{mM} \mathrm{NO}_{3}^{-}$for 5 weeks and were starved for $\mathrm{N}$ during 5 days. Thereafter, the plants were re-supplied with $1 \mathrm{mM} \mathrm{NO}_{3}{ }^{-}$during $4 \mathrm{~h}$. (A) Immunoblot for NRT2.1 using antiNRT2.1(19) antibody. (B) Immunoblot for NRT2.1 using anti-NRT2.1 (20) antibody. Samples were separated on a $12 \%$ SDS-PAGE (10 $\mu \mathrm{g}$ of protein/lane).

(C), (D) and (E) Blue-native PAGE (BN-PAGE) for NRT2.1 and NAR2.1 complex, using microsomes extracted from roots of wild-type (Col) grown on $1 \mathrm{mM} \mathrm{NO}_{3}{ }^{-}$(C) and $\Delta 3 \mathrm{C}_{514-530}$ (D) and $\Delta 5 \mathrm{C}_{494-530}$ (E) transgenic lines, after $4 \mathrm{~h}$ of $\mathrm{NO}_{3}$ - re-supply. Membranes were probed with both anti-NRT2.1 20 and anti-NAR2.1 antibodies. 


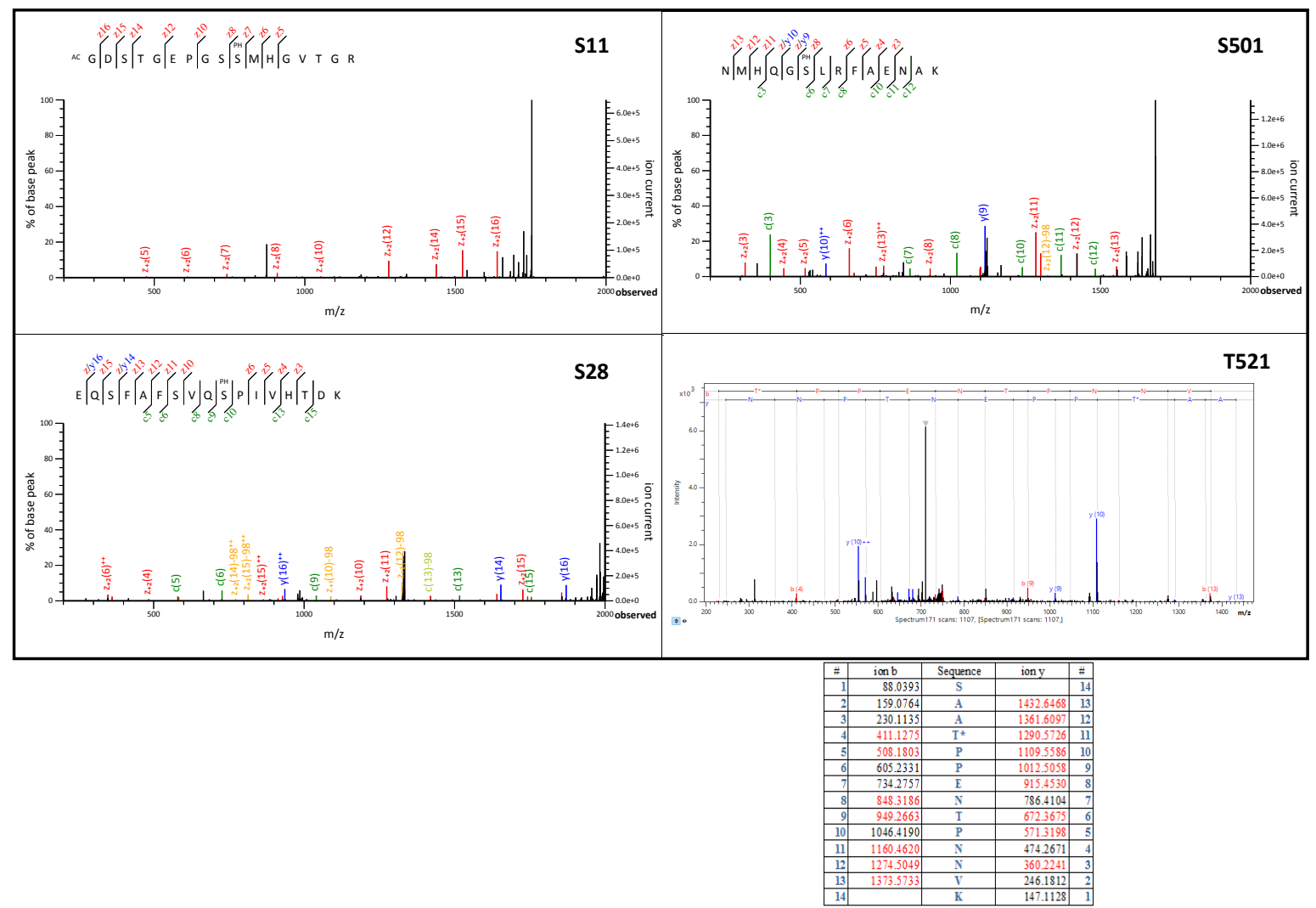

B

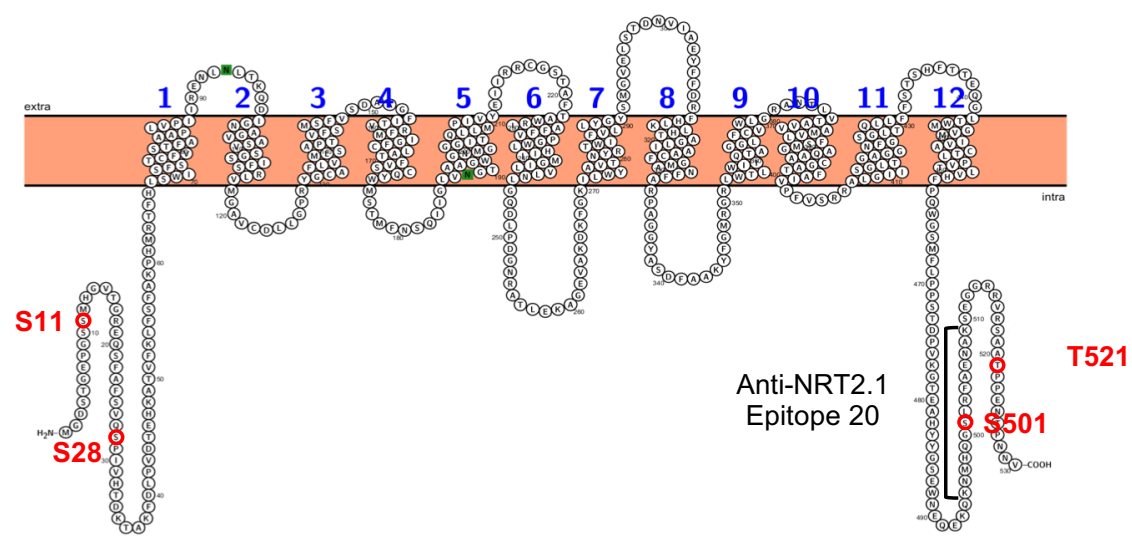

Figure 4. Identification of NRT2.1 phosphorylation sites.

(A) S11 : MS/MS spectrum corresponding to a serie of $z$ ions resulting from ETD fragmentation of NRT2.1 peptide (ion score Mascot 2.6: 67 ; site phosphorylation probability Mascot 2.6: 96.42\%). Data analysis led to the identification of the sequence GDSTGEPGSS*MHGVTGR with phosphorylation of S11. S28 and S501: MS/MS spectrum corresponding to a series of $c$ and $z$ ions resulting from ETD fragmentation of NRT2.1 peptides: S28: ion score Mascot 2.6: 80 ; site phosphorylation probability Mascot 2.6: 99.66\%; S501: ion score Mascot 2.6: 54. Data analysis led to the identification of the sequence EQSFAFSVQS*PIVHTDK with phosphorylation of S28 and of the sequence NMHQGS*LRFAENAK with phosphorylation of S501. T521 : MS/MS spectrum and fragmentation table corresponding to $a$ series of $b$ and $y$ ions that resulted from CID fragmentation of NRT2.1-GFP peptide (ion score Mascot 2.6: 50 ; site phosphorylation probability Mascot 2.6: 92.69\%). Data analysis led to identification of the sequence SAAT*PPENTPNNVK with phosphorylation of T521.

(B) Membrane topology of NRT2.1 using Protter (Omasits et al., 2014), with the epitope corresponding to NRT2.1 antibody (20) and the localisation of the phosphorylation sites identified by mass spectrometry. 
A

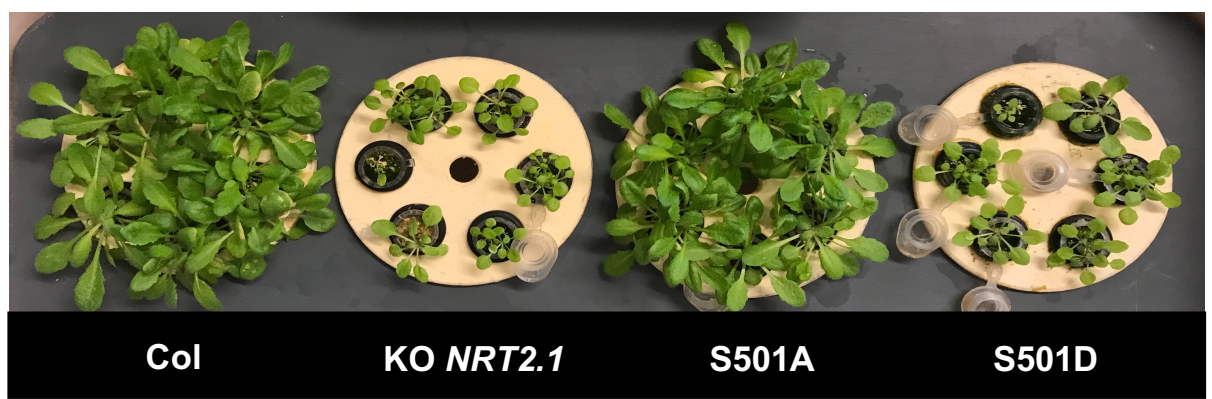

B

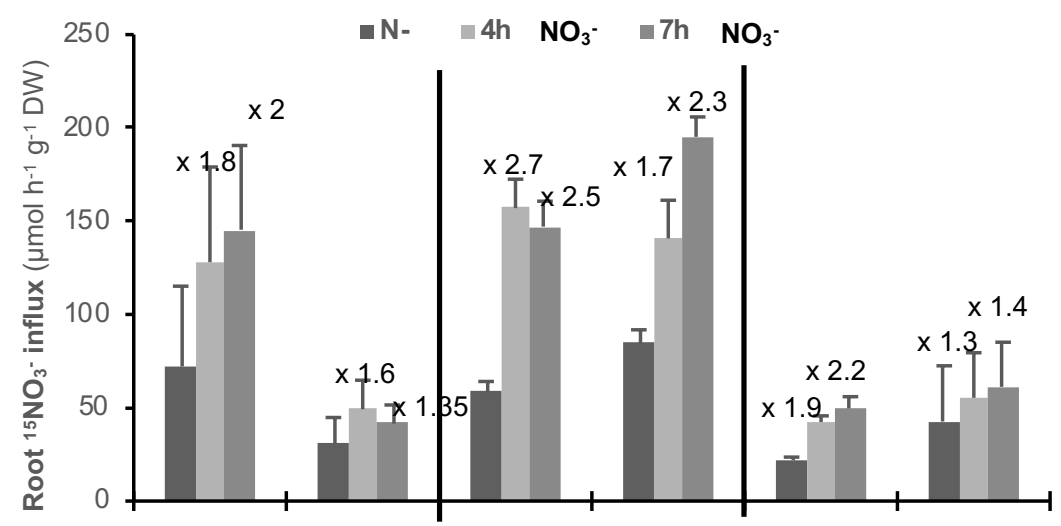

C

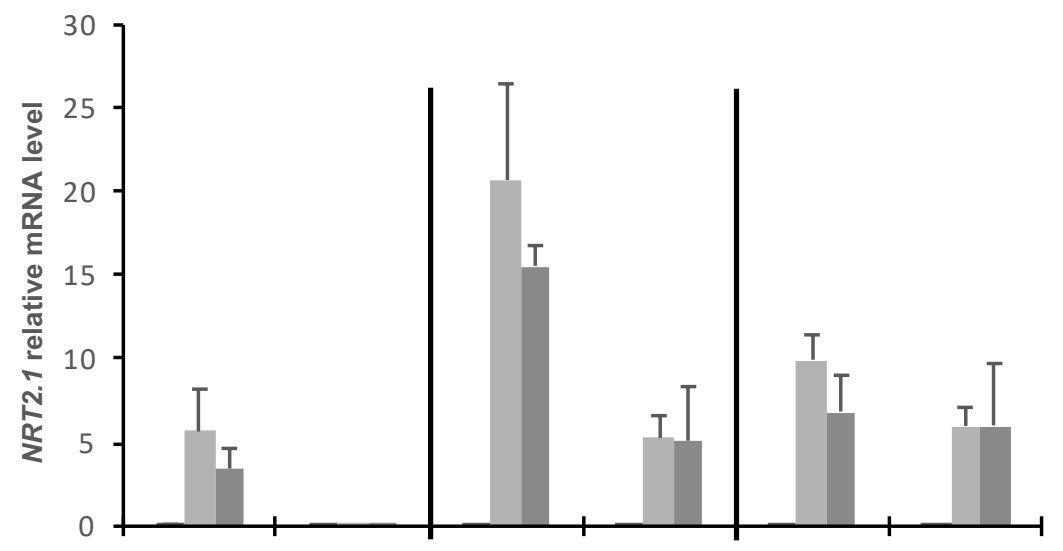

D

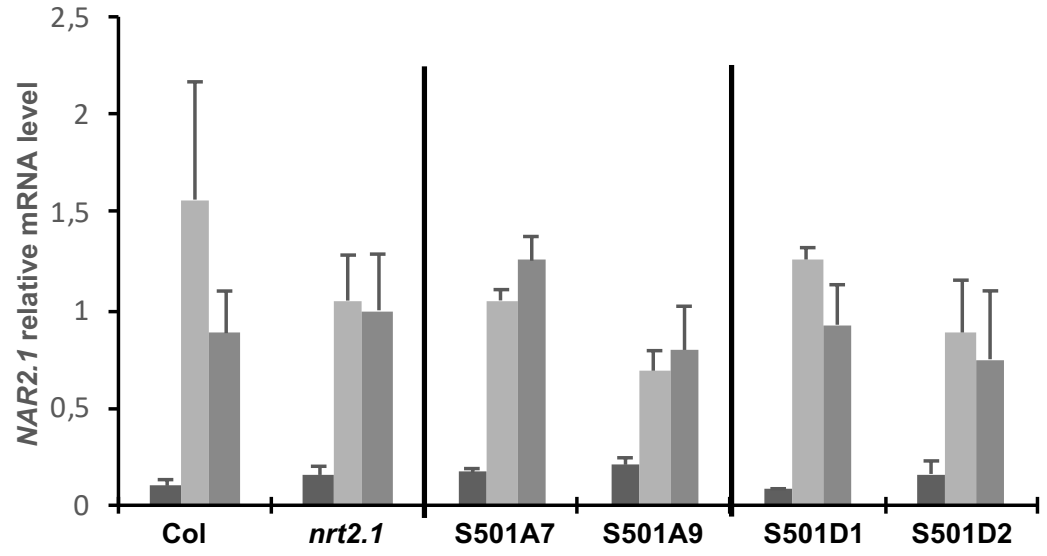

Figure 5. Characterization of Arabidopsis transgenic lines expressing mutated forms of NRT2.1 on the phosphorylation site S501.

Wild type (Col), nrt2.1-2 knockout mutant (nrt2.1) and transgenic lines expressing mutated forms of NRT2.1, which either cannot be phosphorylated (S501A7 and S501A9) or mimic a constitutive phosphorylation of S501 (S501D1 and S501D2). Plants were grown on $1 \mathrm{mM} \mathrm{NO}_{3}{ }^{-}$for 5 weeks and were starved for $\mathrm{N}$ during 5 days. Thereafter, the plants were re-supplied with $1 \mathrm{mM} \mathrm{NO}_{3}{ }^{-}$during $4 \mathrm{~h}$ and $7 \mathrm{~h}$.

(A) Phenotype of the plants grown on $1 \mathrm{mM} \mathrm{NO}_{3}^{-}$.

(B) Root $\mathrm{NO}_{3}{ }^{-}$influx measured at the external concentration of $0.2 \mathrm{mM}^{15} \mathrm{NO}_{3}{ }^{-}$(Values are means of 12 replicates \pm SD).

(C) and (D) Root NRT2.1 and NAR2.1 expression quantified by QPCR (Values are means of three replicates \pm SD). 
A

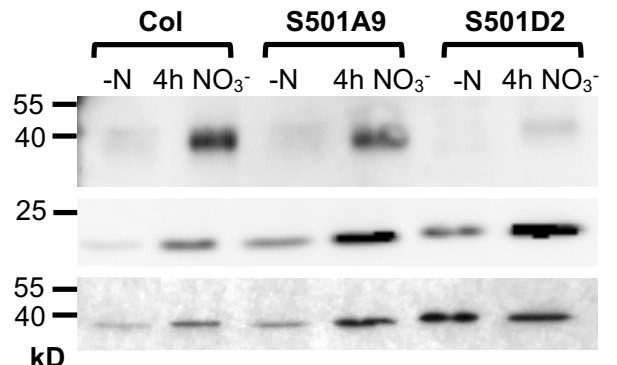

Anti-NRT2.1 19

Anti-NAR2.1

Anti-Actin

B
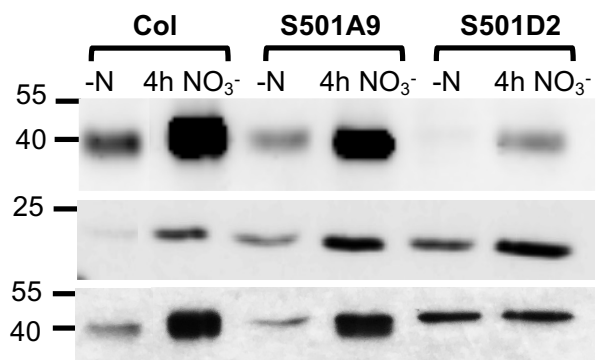

Anti-NRT2.1 20

Anti-NAR2.1

Anti-Actin

$\mathrm{kD}$
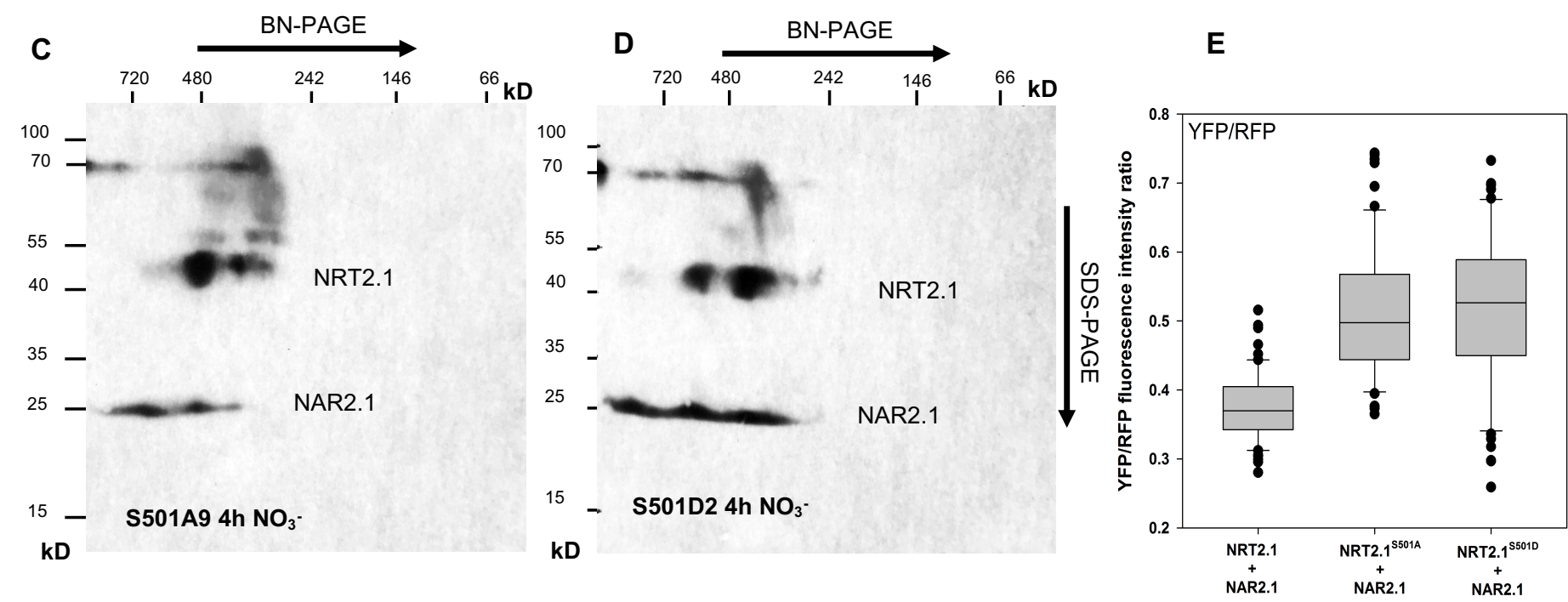

Figure 6. NRT2.1 and NAR2.1 protein level and protein complex in the transgenic lines expressing mutated forms of NRT2.1 for S501 phosphorylation site.

(A) and (B) Immunoblot for NAR2.1 and NRT2.1 using plasma membranes extracted from roots of wild type (Col) and transgenic lines expressing mutated forms of NRT2.1, which either cannot be phosphorylated (S501A9) or mimic a constitutive phosphorylation on S501 (S501D2). Plants were grown on $1 \mathrm{mM} \mathrm{NO}_{3}{ }^{-}$for 5 weeks and were starved for $\mathrm{N}$ during 5 days. Thereafter, the plants were re-supplied with $1 \mathrm{mM} \mathrm{NO}_{3}{ }^{-}$during $4 \mathrm{~h}$. (A) Immunoblot for NRT2.1 using anti-NRT2.1(19) antibody. (B) Immunoblot for NRT2.1 using anti-NRT2.1 (20) antibody. Samples were separated on a $12 \%$ SDS-PAGE (10 $\mu \mathrm{g}$ of protein/lane).

(C) and (D) Blue-native PAGE (BN-PAGE) for NRT2.1 and NAR2.1 complex, using microsomes extracted from roots of S501A9 (C) and S501D2 (D) transgenic lines, after $4 \mathrm{~h}$ of $\mathrm{NO}_{3}$ - re-supply. Membranes were probed with both anti-NRT2.1 (20) and anti-NAR2.1 antibodies.

(E) $\mathrm{rBiFC}$ fluorescence signals from five independent experiments using tobacco plants transformed with the pBiFCt-2in1-CC vector. Each box plot represents the mean of fluorescence intensity ratios from more than 12 images taken at random over the leaf surface. rBiFC signals were calculated as the mean fluorescence intensity ratio of YFP to RFP determined from each image set. 
Anti-S501-P

A

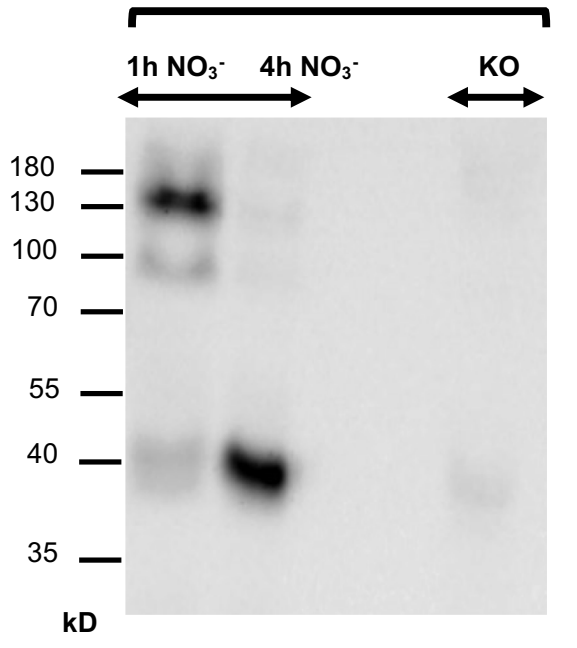

Anti- NRT2.1-20

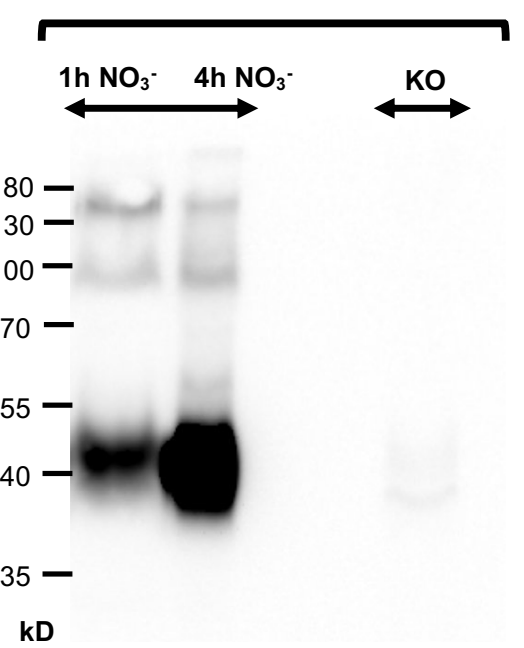

B

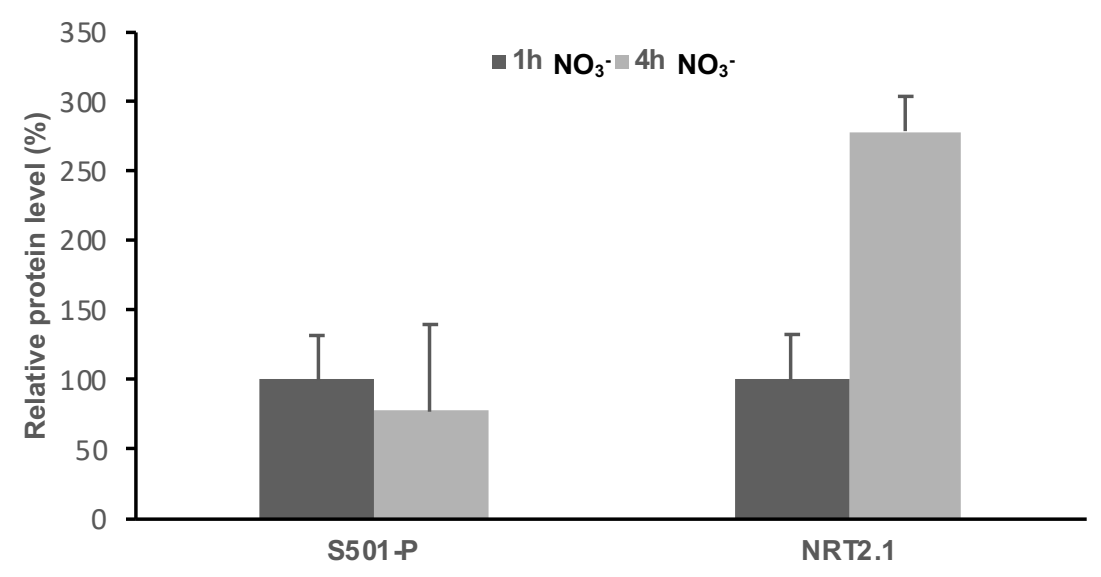

Figure 7. Regulation of NRT2.1 $\mathrm{S} 501$ phosphorylation in response to $\mathrm{NO}_{3}$ -

Wild type plants were grown on $1 \mathrm{mM} \mathrm{NO}_{3}^{-}$for 5 weeks and were starved for $\mathrm{N}$ during 5 days. Thereafter, the plants were re-supplied with $1 \mathrm{mM} \mathrm{NO}_{3}^{-}$during $1 \mathrm{~h}$ or $4 \mathrm{~h}$. Knock-out plants for NRT2.1 (KO) were grown on $1 \mathrm{mM} \mathrm{NO}_{3}^{-}$

(A) Immunoblot for NRT2.1 S501 phosphorylation site (Anti-S501-P) and NRT2.1 (Anti-NRT2.1-20) using microsomes extracted from roots. Samples were separated on a 12\% SDS-PAGE ( $20 \mu \mathrm{g}$ of protein/lane).

(B) ELISA from three independent experiments for NRT2.1 phosphorylation site (S501-P) and NRT2.1 using microsomes extracted from roots. 


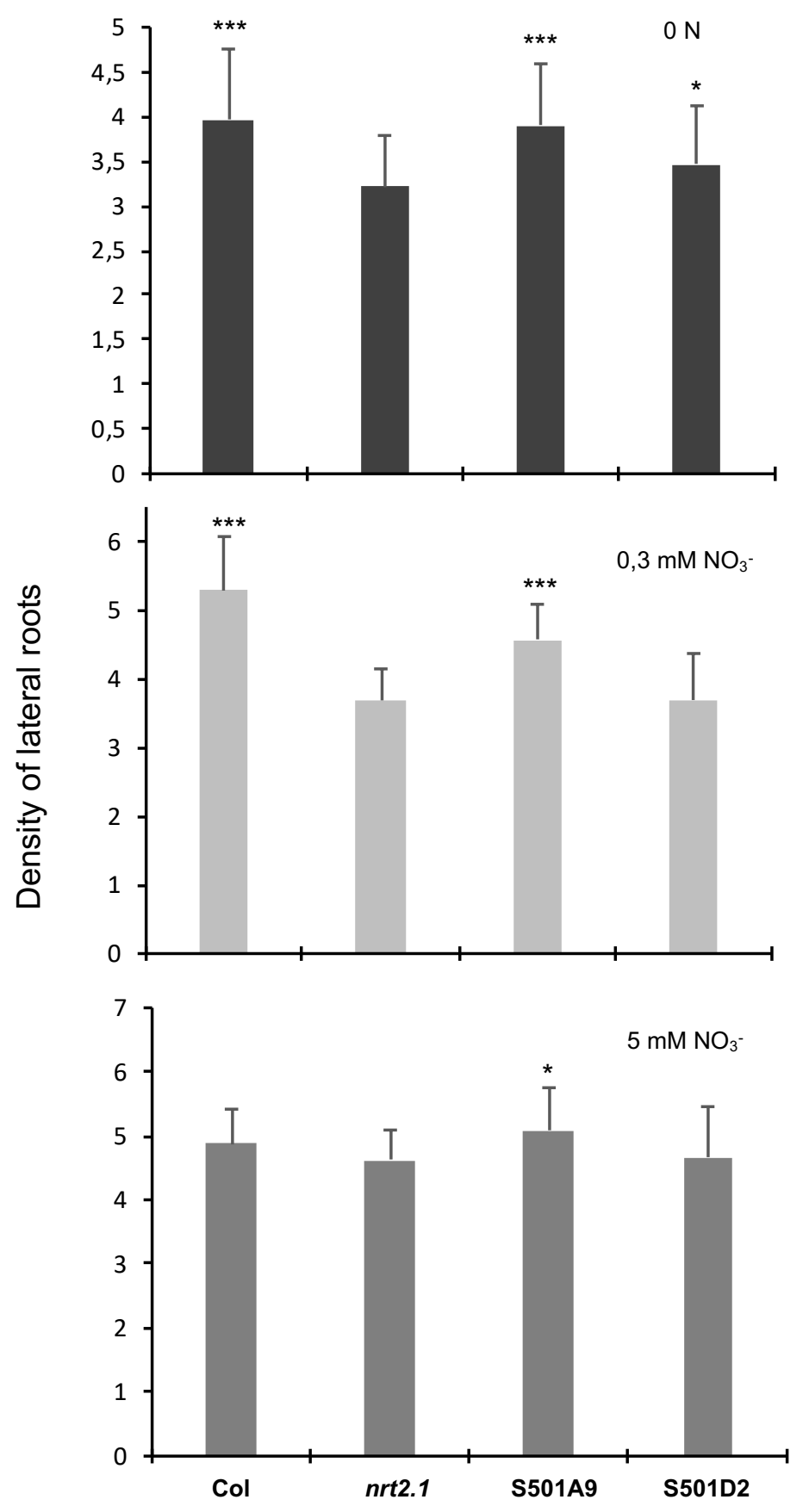

Figure 8. Impact of S501A and S501D mutations on lateral root density in response to $\mathrm{NO}_{3}{ }^{-}$

Density of initiated primordia corresponding to the total number of primordia plus lateral roots normalized by the length of the primary root of wild type (Col), nrt2.1-2 knockout mutant (nrt2.1) and S501A9 or S501D2 transgenic lines. Plants were transferred at day 5 from $1 \mathrm{mM} \mathrm{NO}_{3}{ }^{-}$to either nitrogen-free medium $(0 \mathrm{~N})$ or 0,3 and $5 \mathrm{mM} \mathrm{NO}_{3}{ }^{-}$. Total number of visible LRs and LR primordia were determined between day 10 and 12 . Average values are means of at least 20 replicates $\pm \mathrm{SD}$. ${ }^{*} \mathrm{P}<0.05,{ }^{* *} \mathrm{P}<0.01$ and ${ }^{* * * P}<0,001$ calculated by unpaired Sudents $\mathrm{t}$-test compared to $n r t 2.1$. 

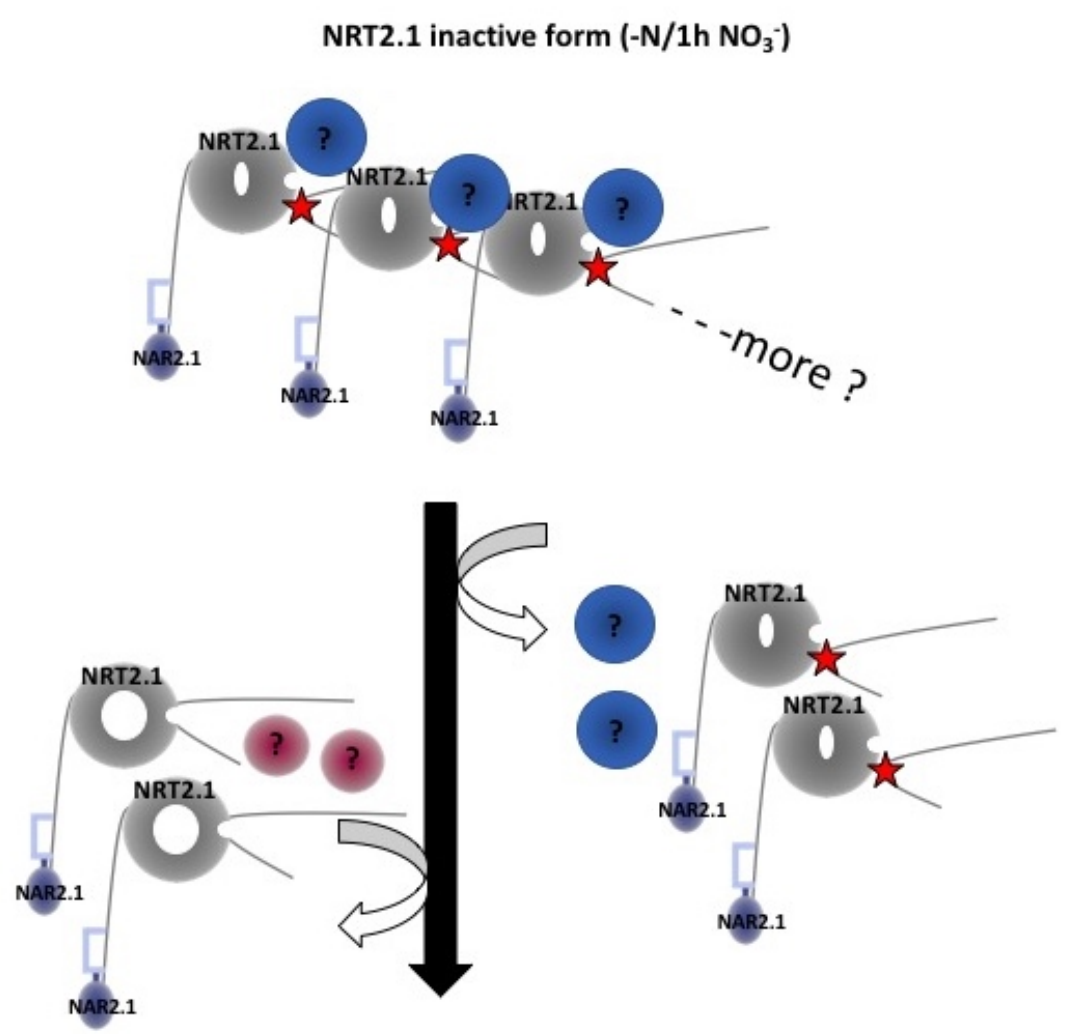

NRT2.1 active form $\left(4 \mathrm{~h} \mathrm{NO}_{3}{ }^{-}\right)$

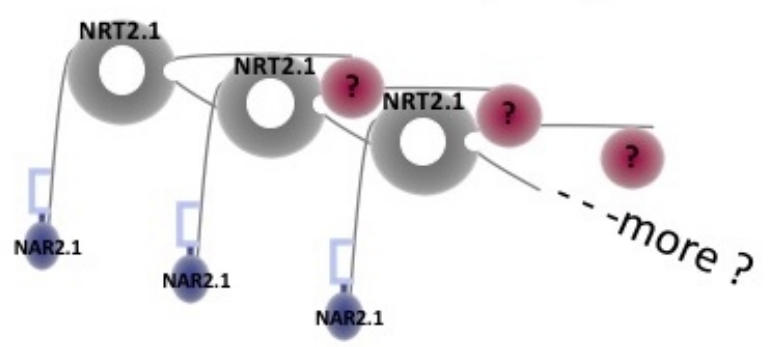

Figure 9. Model for the regulation of NRT2.1 activity

NRT2.1 is represented with NAR2.1 interacting with its N-terminus and the red stars indicate S501 phosphorylation in NRT2.1 C-terminus part. The blue and pink disks represent hypothetical partner proteins, which could respectively participate in the inactivation and the activation of NRT2.1 protein complex. Under non inductive conditions, S501 is phosphorylated, the pores of NRT2.1 are closed and the protein complex is inactive. On inductive conditions, the protein complex with the phosphorylated form of NRT2.1 is dissociated and replaced by a protein complex containing new forms of non-phosphorylated NRT2.1. The absence of NRT2.1 S501 phosphorylation in the protein complex open the pores and enable $\mathrm{NO}_{3}{ }^{-}$to enter the root. 
EctSiNRT2.1-brownalgae MicPuNRT2.1-greenalgae ChlReNRT2.1-greenalgae PhyPaNRT2.1-mosses

Vv14s0066g00850

Vv1s0127g00070

SelMoNRT2 1-2-club-mosses

SelMoNRT2.1-1-club-mosses

PinPiNRT2.1-seedplants

AspofNrt2.1-1-monocots

AmbTrNrt2.1-floweringplants

CamSaNrt2.1-eudicots

AraThNRT2.1-eudicots

RapSaNrt2.1-eudicots

BraJuNRT2.1-eudicots

BraRaNRT2.1-eudicots

ChrMoNRT2.1-eudicots

Vv8s0040g01500

SolLyNRT2.1-eudicots NicTaNRT2.1-eudicots LotJaNrt2.1-eudicots Vv6s0061g00320

PopEunrt2.1-eudicots RicCoNrt2.1-eudicots JatCuNrt2 . 1-eudicots TheCaNrt2.1-eudicots MalHuNRT2.1-eudicots FraVeNrt2.1-eudicots PruPeNRT2.1-eudicots GloElNRT2.1-eudicots SesInNrt2.1-eudicots TriAeNRT2.1-monocots BraDiNrt2.1-monocots HorVuNRT2.1-monocots OrySaNRT2.1-monocots OryBrNrt2.1-monocots SetItNrt2.1-1-monocots SorBiNrt2.1-monocots ZeaMaNRT2.1-1-monocots AnaCoNrt2.1-monocots MusAcNrt2.1-monocots PicAnYNT1-ascomycetes LacBiNrt2.1-basidiomycetes AspclCrnA-ascomycetes

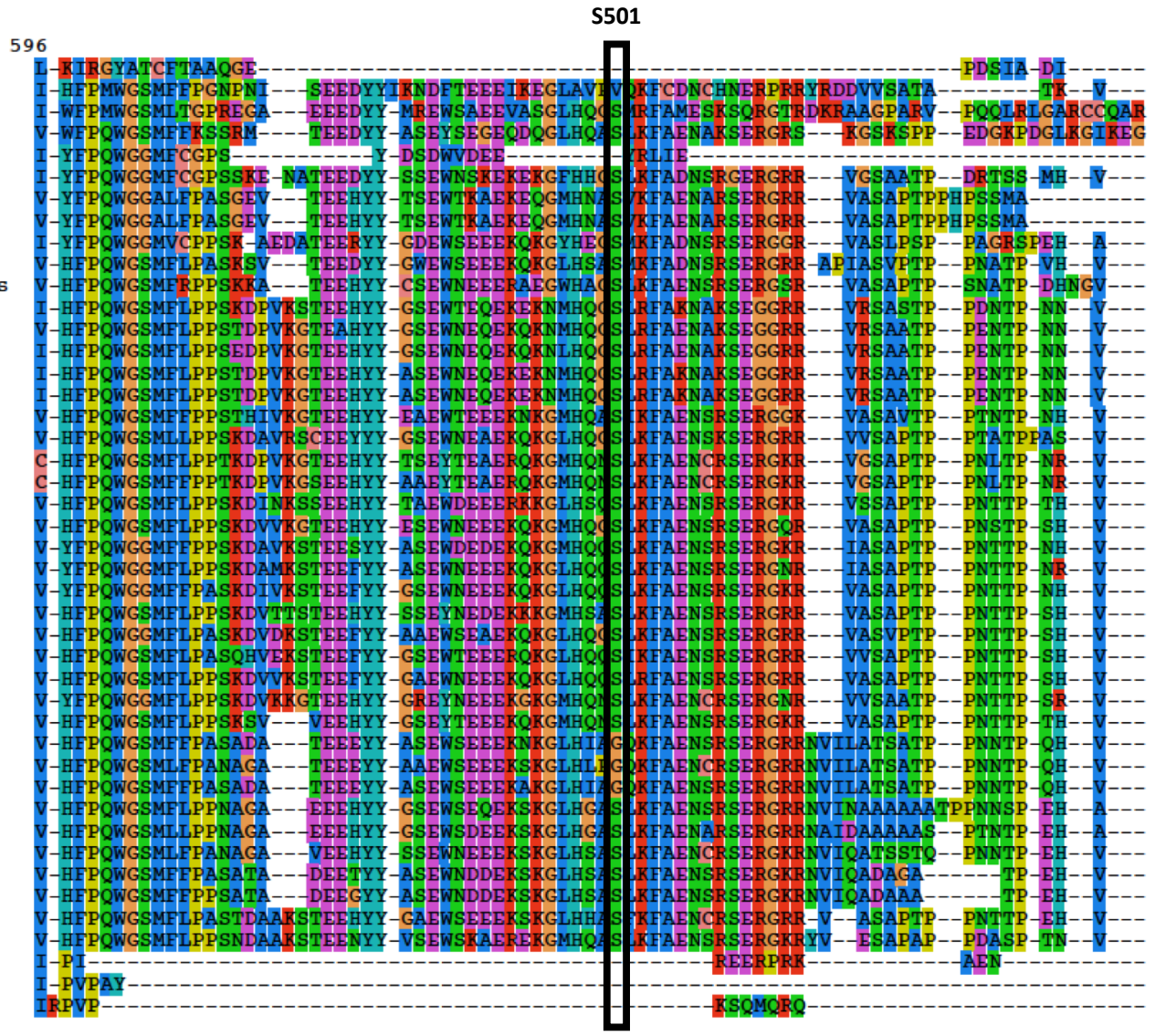

Figure 10. NRT2.1 C-terminus part alignment performed using Muscle v3.8.31 (Edgar, 2004) and displayed with SeaView version 4 (Gouy et al., 2010). 